ESPECIAL 50 ANIVERSARIO

\title{
Los edificios de la Facultad de Ciencias Biológicas y Ambientales de la Universidad de León, entre el recuerdo y el apunte histórico
}

Estanislao Luis Calabuig y Juan Manuel Nieto Nafría

\section{Introducción}

La Universidad de León adoptó a raíz de la Ley Orgánica 11/1983 de Reforma Universitaria - conocida como LRU- una organización sin supeditación entre centros y departamentos, por lo cual no es fácil determinar si un inmueble de la Universidad corresponde en exclusiva a un centro o lo comparte con espacios departamentales. Sin embargo es normal referirse a muchos de los edificios del campus de Vegazana con el nombre de un centro. Entre ellos están los dos edificios de la Facultad de Ciencias Biológicas y Ambientales, según su denominación actual. Ambos se encuentran situados en el extremo sudoccidental de la parte primigenia de ese campus (Fig. 1), la parte urbanizada a comienzos de los setenta del pasado siglo por la Caja de Ahorros y Monte de Piedad de León.

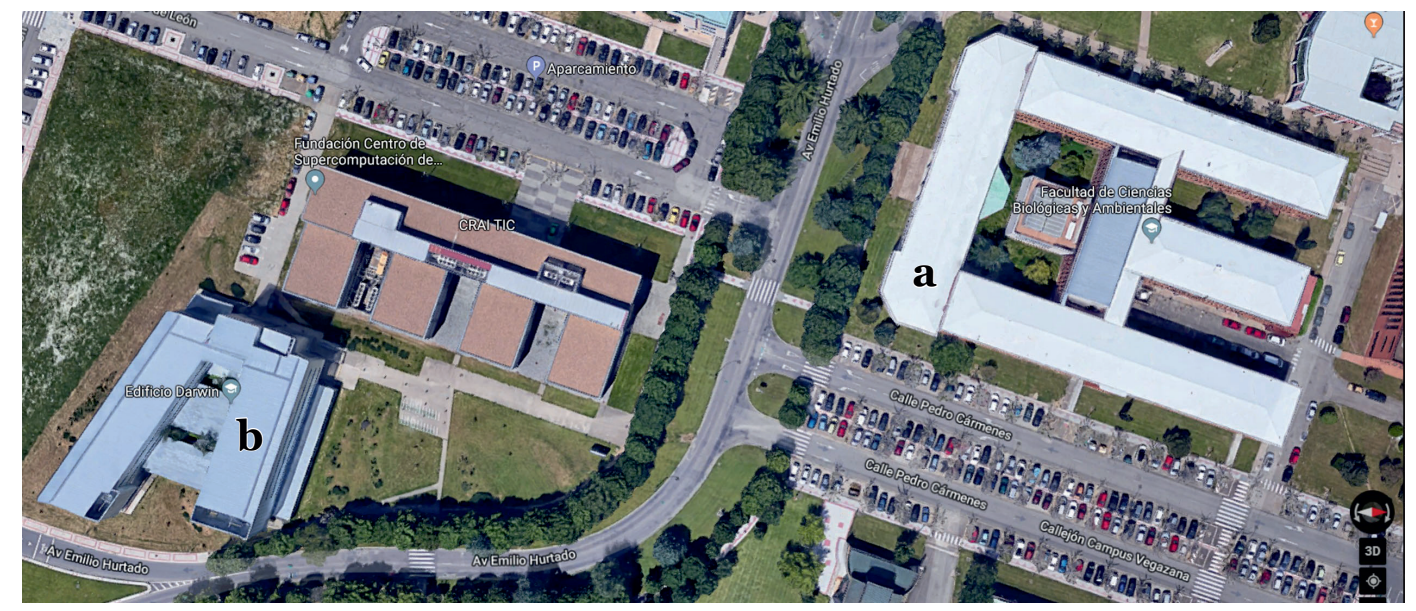

Figura 1. Ubicación en el Campus de Vegazana de los edificios Central (a) y Darwin (b) de la Facultad de Ciencias Biológicas y Ambientales. Fuente: Google Maps.

De los dos, el situado más en el extremo del campus es el de construcción más reciente. Es el primer edificio de la Universidad que se ve al acceder al campus por el extremo occidental de la avenida Emilio Hurtado y no pasa desaper- 
cibido por su revestimiento metálico. Indudablemente es un edificio de la Facultad, porque en él no hay ninguna dependencia departamental.

El otro edificio se encuentra en la avenida Emilio Hurtado, haciendo esquina con la calle Profesor Pedro Cármenes. Es reconocible por su fachada de hormigón y sus laterales de ladrillo visto con ventanas altas y estrechas. Alberga instalaciones de la Facultad en el sentido estatutario del término y de varios departamentos de la Universidad. Desde 2009 se le conoce como Edificio Central, para distinguirlo del Edificio Darwin.

\section{La creación de la Sección de Biológicas de la Facultad de Ciencias de la Universidad de Oviedo; el conflicto}

Si existen edificios de una Facultad, se debe sin duda a que ésta está constituida formalmente. Parece oportuno, por ello, hacer referencia a la creación de la misma, que se remonta a los comienzos de la segunda mitad de la pasada centuria. Los avatares de esa creación los trató con detalle en 1983 y 1995 el Prof. Cordero del Campillo ${ }^{1}$, catedrático de Parasitología y Enfermedades parasitarias e infecciosas de la Facultad de Veterinaria, más adelante primer Presidente de la Sección de Ciencias Biológicas de la Facultad de Ciencias de la Universidad de Oviedo, en León, y Rector de la Universidad de León entre 1984 y 1986.

Los estudios de Ciencias Biológicas en León se establecieron por ORDEN [del Ministerio de Educación Nacional] de 12 de julio de 1961 por la que se crea en la Facultad de Ciencias de la Universidad de Oviedo la Licenciatura en Ciencias Biológicas² firmada por el Ministro [1956-1962] de Educación Nacional D. Jesús Rubio García-Mina que dice:

«El Decreto de 11 de agosto de 1953, al reorganizar los planes de estudio universitarios, estableció en la Sección de Ciencias Naturales de las Facultades de Ciencias la distinción entre las licenciaturas de Ciencias Biológicas y de Ciencias Geológicas, figurando dicha Sección únicamente en las Universidades de Madrid y Barcelona, hasta que por Decreto de 22 de julio de 1958 fueron creadas las Secciones de Ciencias Geológicas en las Facultades de Ciencias de Granada y Oviedo, en atención a la necesidad sentida de ampliar los estudios de ciencias geológicas en nuestro país. / En esta misma línea se impone ahora la necesidad de extender las enseñanzas de las Ciencias Naturales en su rama de biológicas, por lo que se estima conveniente ampliar la Sección de Ciencias Geológicas que funciona en la Facultad de Ciencias de Oviedo incluyendo en la misma las enseñanzas de la licenciatura en Biológicas, mediante la creación de la correspondiente especialidad, que completara la Sección de Naturales de la mencionada Facultad. / En atención a dichas consideraciones, /

\footnotetext{
${ }^{1}$ Cordero del Campillo, Miguel. 1983. La Universidad de León, de la Escuela de Veterinaria a la Universidad. Capítulo VII: Facultad de Biología: páginas 417-433. Editorial Everest. León. Cordero del Campillo, Miguel. 1995. El nacimiento de la Sección de Ciencias Biológicas en la ciudad (1961-1968) de León. En Rodríguez Otero, H. et al.: 25 aniversario de la Facultad de Biología: 19-42. Universidad de León, Servicio de Publicaciones. León.

2 Boletín Oficial del Estado, 1961, núm. 168 <https://www.boe.es/boe/dias/1961/o8/19/pdfs/A1227312273.pdf>
} 
Este Ministerio ha dispuesto: // Primero. Se crea en la Facultad de Ciencias de la Universidad de Oviedo la licenciatura en Ciencias Biológicas. / Segundo. Dicha Sección de Biológicas tendrá su sede en la ciudad de León, del distrito universitario de Oviedo. / Tercero. Las enseñanzas correspondientes a la licenciatura en Ciencias Biológicas que se establecen en la mencionada Universidad por la presente Orden, se implantarán gradualmente, según lo permita la previa dotación necesaria de cátedras y servicios, y se ajustarán al plan de estudios aprobado por Decreto de 11 de agosto de 1953. / Cuarto. Por esa dirección General se dictarán las disposiciones que sean necesarias para la ejecución de lo que se establece en la presente Orden.»

En la Universidad de Oviedo nadie estaba al tanto de la decisión gubernamental y tras la publicación de la Orden la Junta de la Facultad de Ciencias acordó elevar al Ministerio un informe para hacer ver los «inconvenientes de tipo pedagógico, económico y de organización que iba a implicar dicha Sección» y solicitar que se implantara en Oviedo (Cordero del Campillo, 1983).

Alguien -no sabemos quién- debió manejar en el Ministerio los hilos adecuados para que los estudios de Ciencias Biológicas se establecieran en León al amor de la Facultad de Veterinaria, rebajando así los costes materiales y de personal de su puesta en marcha, al tiempo que se daba una mayor ocupación a un profesorado que parecía estar infrautilizado.

Es revelador de esta creación vinculada las palabras pronunciadas muchos años después por el Dr. D. Jaime Andrés Rodríguez - a la sazón profesor adjunto de Botánica y uno de los antiguos de la casa- en una sesión del Claustro de la Facultad: «Me gustaría que este Claustro hiciese un breve examen histórico de como se gestó esta Facultad. Como nació completamente ligada a Veterinaria y como hubiese sido imposible sacarla adelante con un mínimo decoro sin el Apoyo de la Facultad de Veterinaria. [...] [a ella] pertenecieron todos los profesores de los primeros tiempos (Cordero, Ovejero, Zorita, Martínez, Guerra, Vigil, Escudero, etc.). Todos alojaron en sus laboratorios a los alumnos de Biológicas sin tener la más mínima consignación para ello. Y dieron sus clases durante años, sin cobrar absolutamente nada» 3 .

La ORDEN (del Ministerio de Educación y Ciencia) de 27 de julio de 1968 por la que se resuelve que la licenciatura de la Sección de Ciencias Biológicas de la Universidad de Oviedo tendrá dos ramas: una de Biología general y otra de Biología animal ${ }^{4}$ que firmó el Ministro [1968-1973] D. José Luis Villar l'aliısí. no deja lugar a dudas de lo correcto de esa interpretación de la motivación. Dice:

«La Orden ministerial de 12 de julio de 1961 («Boletín Oficial del Estado» de 19 de agosto) creó en la Facultad de Ciencias de la Universidad de Oviedo la Sección de Ciencias Biológicas, con sede en la ciudad de León. /// El progresivo auge de las Ciencias Biológicas, la conveniencia de señalar en ellos campos de especialización y la

${ }^{3}$ Libro de Actas CLAUSTRO, sesión del 25 de marzo de 1976, páginas 13 cara y vuelta.

4 Boletín Oficial del Estado, 1968, núm. 199 <https://www.boe.es/boe/dias/1968/08/19/pdfs/A1225312254.pdf> 
circunstancia de existir en la ciudad de León una Facultad de Veterinaria, cuyo profesorado e instalaciones pueden cooperar al desarrollo de dichas enseñanzas, junto con la creciente necesidad de licenciados para atender la demanda de profesorado de enseñanza media y el hecho de contar la Universidad ovetense con la Facultad de Ciencias, con sus Secciones de Químicas y Geológicas, aconsejan replantear el problema, coodinario [sic, por coordinando] el desarrollo de las enseñanzas del modo más eficaz, con los criterios racionales y utilizando al máximo los recursos de instalaciones y profesorado ya existentes. / En atención a dichas circunstancias y de conformidad con lo dispuesto en el artículo 20 y en la disposición final del Decreto de 11 de agosto de 1953 [Decreto de Establecimiento de los planes de estudio de las Facultades Universitarias de Filosofía y letras, Ciencias, Derecho, Medicina, Veterinaria y Ciencias Políticas, Económicas y Comerciales, BOE del 19 de agosto] y con la propuesta formulada por la Facultad de Ciencias de dicha Universidad elevada por conducto del Rectorado de la misma: // Este Ministerio ha resuelto: / $10^{\circ}$ La licenciatura de la Sección de Ciencias Biológicas de la Universidad de Oviedo tendrá dos ramas: Una de Biología General y otra de Biología Animal. / 2. ${ }^{\circ}$ La rama de Biología General tendrá su sede en la ciudad de Oviedo, coordinándose sus enseñanzas con las de otras Secciones de Ciencias de dicha ciudad [a la sazón Químicas y Geológicas]. / 3. ${ }^{\circ} \mathrm{La}$ rama de Biología Animal tendrá su sede en la ciudad de León, coordinándose sus enseñanzas con Facultad de Veterinaria de dicha ciudad en cuanto respecta a los locales, profesorado y demás servicios que se estime procedentes. $/ 4 .{ }^{\circ}$ Las enseñanzas correspondientes a los dos ramas comenzarán con el curso 1968-69, por el Selectivo de la Facultad de Ciencias y de Veterinaria. Los cursos segundo y tercero serán comunes para ambas ramas y se implantarán gradualmente, al igual que los cursos cuarto y quinto de especialización, todo ello previa aprobación de los respectivos planes de estudios. / 5. ${ }^{\circ}$ Queda autorizada esa Dirección General para dictar las disposiciones que sean necesarias para la ejecución de cuanto establece la presente Orden.»

Nótese el cambio de nombre tanto del ministerio como de la Dirección general con relación a la Orden de 1961; esos años vieron un cambio en la organización universitaria española que culminaría con la Ley 14/197o General de Educación y Financiamiento de la Reforma Educativa del 4 de agosto.

Mediante esa Orden se atendía, además, de algún modo la petición de la Facultad de Ciencias de la Universidad de Oviedo, que contaba con el respaldo del rectorado de la Universidad, petición que en la Orden se califica de problema.

Es evidente que ese problema retrasó varios años la puesta en marcha de la Sección, al tiempo que se pusieron en marcha estudios de Ciencias Biológicas en las universidades de Salamanca y Sevilla (1965) y se establecieron en las de La Laguna, Santiago, Granada y Valencia.

Ha sido norma común que los estudios universitarios se establecieran para después habilitar los medios personales y materiales necesarios para ir poniéndolos en funcionamiento curso a curso; hay ejemplos de ello tanto en estu- 
dios de Ciencias Biológicas de otras Universidades como en otros estudios en esta misma Universidad de León.

No se han de tratar aquí los medios personales, pero ayuda a comprender el problema de los edificios conocer que los primeros catedráticos - sin considerar la presencia del catedrático de Antropología Dr. Pons Rosell, responsable de la enseñanza de Biología de primer curso en la Facultad de Ciencias de Oviedo5no llegaran hasta $1967 \mathrm{y}$ que sus respectivas incorporaciones tuvieran sus peculiaridades, así: 1. $^{\circ}$ ) D. Matías Mayor López y D. Emilio Anadón Frutos fueron nombrados catedráticos numerarios de la Facultad de Ciencias de la Universidad de Oviedo respectivamente de Botánica (Criptogamia y Fanerogamia) y de Zoología (Invertebrados no Artrópodos) por órdenes ministeriales del 31 de marzo ${ }^{6}$ y del 27 de junio $1967^{7}$, fechas en la que León era la única sede de los estudios de Ciencias Biológicas de esa Universidad, pese a lo cual siempre ejercieron en Oviedo; $2^{\circ}$ ) D. Jacinto Nadal y Puigdefábregas fue nombrado «Catedrático de Zoología (Vertebrados) de la Facultad de Ciencias de León, correspondiente a la Universidad de Oviedo" por Orden de 21 de noviembre de $1970^{8}$, aunque ni ese momento ni nunca ha habido en León un centro universitario denominado de Ciencias; y $3 .^{\circ}$ ) D. Jesús Izco Sevillano y D. José María Basabe Prado fueron nombrados respectivamente profesores agregados de Botánica (Fanerogamia) y de Antropología, respectivamente por órdenes ministeriales de 22 de junio de $1970^{9}$ y de 22 de junio de $1973^{10}$, de la Facultad de Ciencias de la Universidad de Oviedo sin mayor concreción y ambos ejercieron en León.

Los inmuebles jugaron un papel importantísimo en el conflicto. El 9 de noviembre de 1965 se publicó la RESOLUCIÓN de la Subsecretaría [del Ministerio de Educación Nacional] por la que se hace público haber sido adjudicadas [el 5 de octubre] las obras de ampliación de la Facultad de Ciencias de la Universidad de Oviedo, correspondientes a la «Sección de Geológicas y Biológicas», lo cual era un imposible físico, porque cada una de esas secciones radicaba en una ciudad diferente. El edificio se levantó según proyecto del arquitecto D. Ignacio Álvarez Castelao.

\footnotetext{
5 Boletín Oficial del Estado, 1962, núm. 69 < https://www.boe.es/boe/dias/1962/o3/21/pdfs/Ao387803878.pdf>

6 Boletín Oficial del Estado, 1967, núm. 93 <https://www.boe.es/boe/dias/1967/o4/19/pdfs/Ao516105161.pdf>

7 Boletín Oficial del Estado, 1967, núm. 1179 <https://www.boe.es/boe/dias/1967/o7/28/pdfs/A1069310693.pdf>

8 Boletín Oficial del Estado, 1970, núm. 293 <https://www.boe.es/boe/dias/1970/12/o8/pdfs/A1996919969.pdf>

9 Boletín Oficial del Estado, 1970, núm. 170 <https://www.boe.es/boe/dias/1970/o7/o6/pdfs/A1061810618.pdf>

10 Boletín Oficial del Estado, 1973, núm. 177 <https://www.boe.es/boe/dias/1973/o7/25/pdfs/A1514515145.pdf>
} 
La existencia de ese proyecto y más tarde del edificio, reforzó la posición de quienes consideraban que los estudios debían establecerse en Oviedo, porque allí había espacios suficientes y adecuados, mientras que en León los que se habrían de compartir con Veterinaria no parecían ser suficientes, incluso después elevarse un piso el edificio del paseo de la Facultad ${ }^{11}$.

Cordero del Campillo (1983) narra la "inspección" que el Prof. García de Figuerola, catedrático de Petrología y decano de la Facultad de Ciencias, y el Prof. Anadón Frutos hicieron de las instalaciones de la Facultad de Veterinaria al comienzo del curso 1968-1969. El Dr. García de Figuerola informó de la visita en la sesión de la Junta de la Facultad de Ciencias de Oviedo del 9 de septiembre de 1968, lo hizo de forma sucinta y sin dar conclusiones o calificaciones. En esa sesión se acordó solicitar a la Dirección General que se autorizara a la Facultad a impartir durante el año académico próximo a iniciarse, el segundo curso de carrera, tanto en Oviedo como en León, en el cual se podrían matricular quienes hubieran cursado ya el primer curso, que era el común Selectivo de Ciencias y Técnicas, lo cual daba una completa seguridad de que la matricula en Oviedo iba a ser superior a la de León, como así sucedió.

\section{Un edificio para la Sección}

Se daba por hecho que las asignaturas de Ciencias Biológicas con denominación igual o similar a otras de Veterinaria compartirían medios humanos y materiales. Durante la puesta en marcha la Sección se fueron definiendo en el edificio de esa Facultad espacios propios para las cátedras de Zoología, de Botánica y de Antropología. Téngase en cuenta que en el plan de estudios en vigor de la denominada rama de Biología Animal no había asignatura de Fisiología Vegetal y que la única asignatura de Ecología estaba emplazada en quinto de carrera.

Pero los espacios exclusivos eran pequeños, la matrícula en Veterinaria remontaba, la de Ciencias Biológicas aumentaba y se estimó que era necesario un edificio para atender a las necesidades de la Sección de Ciencias Biológicas en León, así en la sesión de la Junta de la Facultad de Ciencias de la Universidad de Oviedo del 15 de enero de 1974 el Decano informó haber insistido ante el Rectorado con la urgencia de esa construcción.

Durante esos años, 1968 a 1977 el profesorado de la Sección que no tenía docencia en Veterinaria se incrementó y aumentó la necesidad de laboratorios para clases prácticas y de aulas para mejorar los horarios, y la reclamación de un edificio fue una constante en las reuniones de los órganos de gobierno de la

11 RESOLUCIÓN de la Subsecretaría de Educación y Ciencias, por la que se hace público haber sido adjudicadas las obras de elevación de un piso en la Facultad de Veterinaria de León. Boletín Oficial del Estado, 1967, núm. 282 < https://www.boe.es/boe/dias/1967/11/25/pdfs/A16328-16328.pdf> 
Sección primero y de la Facultad después ${ }^{12}$. Pero como del edificio nada se sabía se fueron colonizando espacios en las escuelas universitarias de Ingenieros Técnicos de Minas, por Bioquímica y por Genética, y de Ingenieros Técnicos Agrícolas - a pesar de la distancia - por Citología e Histología y por Ecología y para las prácticas docentes por Zoología, así como de la Escuela Universitaria de Estudios Empresariales, aunque solamente para clases.

Se pensaba entonces que el edificio de la Sección debería estar cerca del de Veterinaria y la Diputación Provincial inició los trámites para una cesión del solar necesario, junto al del Conservatorio de Música y al solar a ocupar por la actual Biblioteca Pública (Cordero del Campillo, 1983: 431, nota 3, que refiere un informe en sesión del 8 de noviembre de 1974 de la Junta de Facultad de Veterinaria). Pero «los trámites [...] retrasaron la obra, de tal manera que nada se había llevado a cabo, salvo el proyecto, cuando la Caja de Ahorros [de León], que había comprado la «Huerta del Obispo» para convertirla en campus [en cursiva en el original] universitario, ofreció solares para la Facultad de Biología, en enero de 1977, reiterando ofertas previas, siendo director general don Luis Suárez» (Cordero del Campillo, 1983: 428).

Efectivamente la cesión se produjo el 13 de diciembre de 1976 y el 14 la Junta de Gobierno de la Universidad de Oviedo se dio por enterada, iniciándose ante el Ministerio las gestiones pertinentes para iniciar las obras, «donde prometieron, formalmente, que existían 15 millones de pesetas para comenzar el edificio en el año 1977»13. Sin embargo la cesión del terreno no se formalizó, con su aceptación por el Estado, hasta marzo de $1978^{14}$ y fue entonces cuando pudieron comenzar las obras. De hecho en la sesión de la Junta de Facultad del 6 de abril de 1978 el Decano D. Eduardo Cadenas Bergua -catedrático de Bioquímica-informó que habían comenzado los trabajos de explanación de la parcela ${ }^{15}$.

\section{La primera fase del edificio}

El edificio a levantar había sido proyectado en 1974 por el arquitecto D. Ignacio Álvarez Castelao, el mismo que había proyectado el edificio de Geológicas y Biológicas de Oviedo. Constaba de dos módulos de superficie rectangular (Fig. 2a) con espacios para despachos y salas de mediano tamaño, aptas para bibliotecas o seminarios, pero no para laboratorios de prácticas o de investiga-

\footnotetext{
12 Libro de Actas del Claustro, sesión del 29 de enero de 1976, página 4 cara; sesión del 24 de febrero de 1976, página 9 vuelta; sesión del 16 de septiembre de 1976, página 36 vuelta. Libro de Actas I de la Junta de Facultad, sesión del 17 de marzo de 1978, página 76 vuelta.

13 Libro de Actas del Claustro, páginas 40 cara y vuelta.

14 REAL DECRETO 534/1978, de 2 de marzo, por el que se acepta la donación al Estado por la Caja de Ahorros y Monte de Piedad de León de 7.367.25 metros cuadrados, sito en el término municipal de León, con desino a la construcción de un edificio destinado a Facultad de Ciencias Biológicas de la Universidad de Oviedo. Boletín Oficial del Estado, 1978, núm. 79 <https:/www.boe.es/boe/dias/1978/03/22/pdfs/A06821-06821.pdf>

15 Libro de Actas I de la Junta de Facultad, página 81, vuelta.
} 
ción porque carecían de instalaciones de agua y de fuerza eléctrica, más un aulario, que al poco era conocido como el platillo volante (Fig. $3 \mathbf{a}$ y $\mathbf{3} \mathbf{b}$ ), que dispondría de tres aulas grandes y dos de mediana capacidad, con un amplio distribuidor central conectado con los módulos de departamentos. En conjunto el edificio recordaba al mencionado de Oviedo, que tenía un aulario -el caracol- también separado del edificio de despachos y laboratorios (Fig. 3c). Bien a las claras era un edificio ideado para construirse cerca del de Veterinaria, para así seguir haciendo uso de sus instalaciones, y no en el campus donde aún no había idea de construir el edificio de la Facultad de Veterinaria que ahora existe. En el proyecto constaba una reserva de espacio para levantar otros dos módulos (Fig. 4).

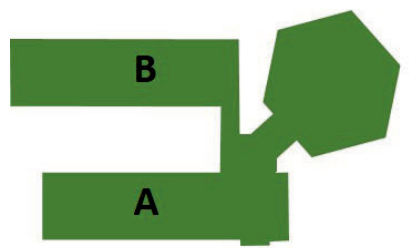

a

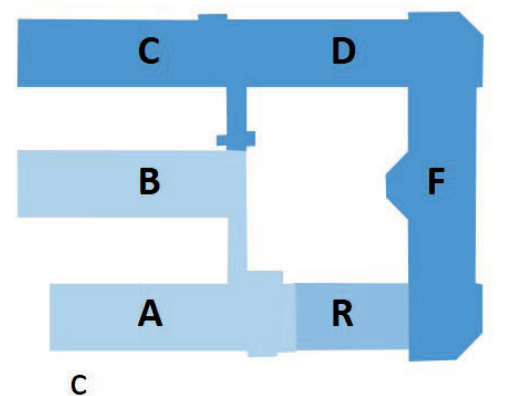

C

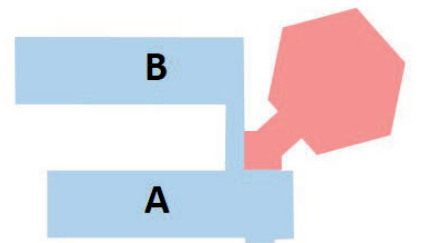

b1

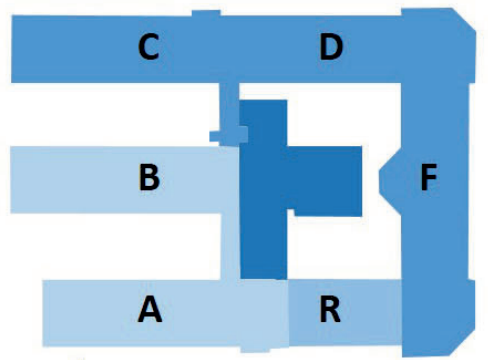

d

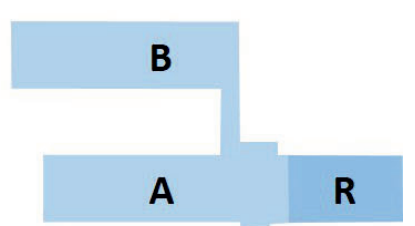

b2

\footnotetext{
Proyecto original primera fase

Desarrollo de la primera fase

Sector eliminado del proyecto de la primera fase

Sector añadido al desarrollo de la primera fase

Desarrollo de la segunda fase

Desarrollo de la tercera fase

Edificio Darwin
}

Figura 2. Evolución de fases construidas en los edificios de la actual Facultad de Ciencias Biológicas y Ambientales. Sobre el proyecto original de la primera fase (a) se propuso la eliminación del módulo del aulario (b1) y ampliar el edificio con el módulo del reformado (b2). La segunda fase desarrolló todo el sector este siguiendo el mismo diseño exterior, y la fachada principal sur de diferente diseño y solamente con dos pisos (c). Con la tercera fase se edificó en el patio un módulo en el sector norte, adosado al pasillo de conexión de los anteriores módulos de departamentos y la extensión de un bloque central (d). Finalmente, en diferente ubicación, se construyó el edificio Darwin con módulos de aulario y laboratorios (e). 


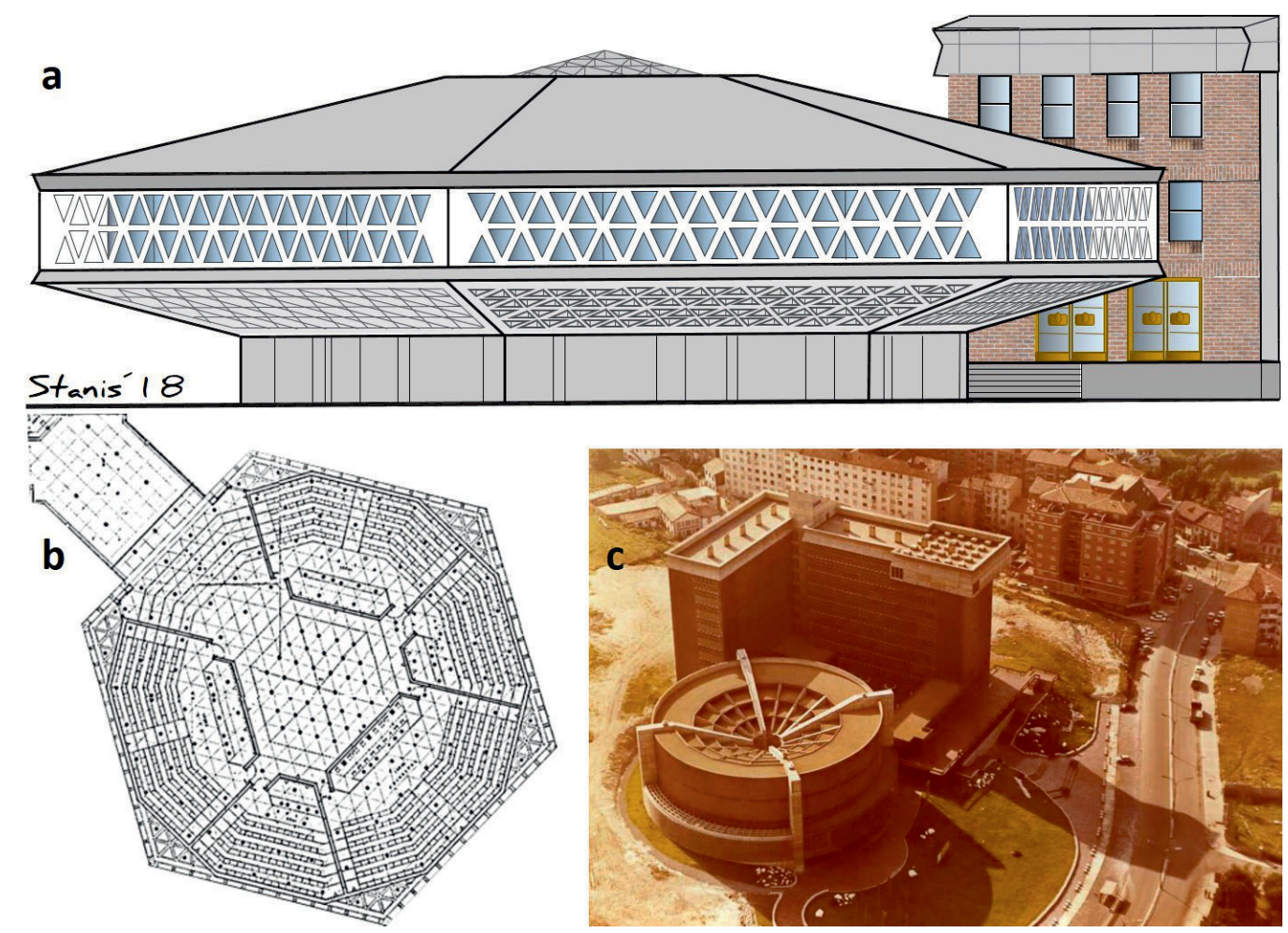

Figura 3. (a) Recreación del alzado del proyecto de aulario en base a los planos originales del arquitecto Álvarez Castelao, coloquialmente conocido como platillo volante (dibujo de E. Luis Calabuig). (b) Planta del aulario proyectado en la primera fase. (c) Aulario de la Facultad de Geológicas de la Universidad de Oviedo, conocido como el caracol.

Debido a los retrasos en la ejecución del proyecto el Sr. Álvarez Castelao cedió el proyecto a la Junta de Construcciones, Instalaciones y Equipo Escolar, organismo autónomo de los Ministerios de Hacienda y de Educación (L. Roy com. pers.), que lo utilizó sin modificación que conozcamos. La obra fue adjudicada a Huarte S.A. y Sastrón con un presupuesto de 110 millones de pesetas.

Figura 4. Proyecto original en el marco de la ordenación urbanística diseñada, donde quedan marcados los espacios para dos futuros módulos, ya en el Campus de Vegazana.

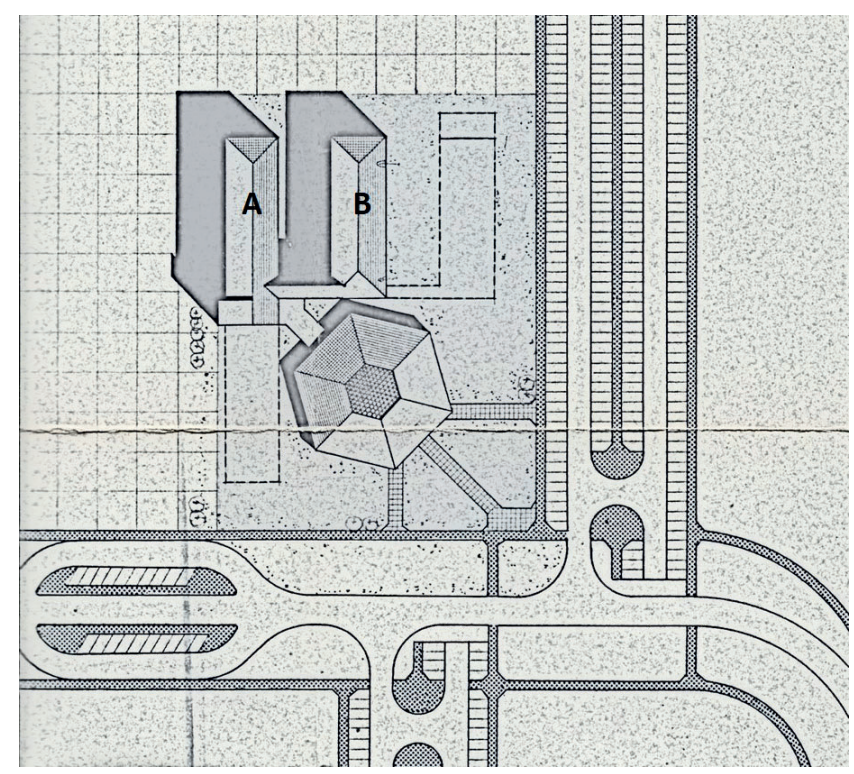


De inmediato se vio la necesidad modificar el proyecto de los módulos rectangulares, llamamos A y B, para poder instalar en ellos laboratorios de docencia y de investigación, lo que implicaba decidir si al nuevo edificio se desplazarían todos los departamentos o solamente algunos, y en este caso cuáles. El asunto se comenzó a debatir en la sesión de la Junta de Facultad del 6 de abril de 197816 . En la sesión del lunes 10 de abril ${ }^{17}$ se adoptaron dos acuerdos trascendentes, uno el de reducir el número de edificios ocupados, desocupando Veterinaria «por razones evidentes» y Agrícolas por razones de distancia - a propuesta del profesor adjunto de Zoología Dr. Salgado Costas-, y otro que todas las clases de la licenciatura se diesen en el edificio nuevo, aunque no estuvieran allí todos los departamentos - a propuesta de la profesora adjunta de Química Dra. Alemany Juárez-. Se trató también la conveniencia de solicitar la inmediata utilización de las dos reservas de espacio, pero se acordó esperar a que se promulgase la ley de creación de la Universidad de León. Acuerdo este último que no se cumplió, pues consta la existencia de dos escritos del Sr. Decano fechados el 3 de mayo dirigidos al Sr. Director General de Universidades y al Sr. Presidente de la Junta de Construcciones, Instalaciones y Equipo escolar, que no han podido ser localizados, a sugerencia del Rector - de la Universidad de Oviedo, Prof. D. Teodoro López Cuesta, que más tarde fue Rector Honorario de la Universidad de León- quien le había recomendado «que estableciera contacto con el Sr. Castelao [sic] para que comenzara la elaboración del anteproyecto de ampliación» 18 .

La Distribución de espacios en el nuevo edificio se retomó en la sesión de la Junta de Facultad del 28 de junio de 1978, y a propuesta del profesor agregado de Zoología (Artrópodos) Dr. Nieto Nafría se acordó por unanimidad19: 1) asignar a Bioquímica, incluyendo Química, el gran espacio existente en la planta baja del módulo B para laboratorio de prácticas, 2) asignar las plantas primera y segunda de ese edificio respectivamente a Zoología (que en caso de necesidad acogería a Fisiología Animal, de hecho allí tuvo su despacho el profesor agregado Dr. D. Luis Palacios Raufast durante su corta estancia en la Facultad) y a Botánica (que seguiría acogiendo a Fisiología Vegetal), y 3) asignar las plantas primera y segunda del módulo A respectivamente a Citología e Histología (1/2 de planta) más Antropología (1/2 de planta) y a Ecología (3/4 de planta) más Matemáticas (1/4 de planta). También se acordó la distribución de la planta baja para los servicios generales de la Facultad: biblioteca, secretaría, decanato, sala de juntas, conserjería y delegación de alumnos, y así mismo el destino de unos pequeños espacios en la planta baja del módulo $B$, en la que además del mencionado labo-

\footnotetext{
16 Libro de Actas I de la Junta de Facultad, páginas 83 vuelta y 84 cara.

17 Libro de Actas I de la Junta de Facultad, páginas 86 vuelta a 87 vuelta.

18 Libro de Actas I de la Junta de Facultad, sesión del 20 de abril de 1978, página 88 vuelta.

19 Libro de Actas I de la Junta de Facultad, páginas 96 cara a 97 vuelta.
} 
ratorio para Bioquímica se encontraba la amplia sala de calefacción, el cuarto del generador eléctrico y la vivienda del conserje, que desde la inauguración del edificio hasta el día de hoy, próximo a su jubilación, ha ocupado D. Jesús Álvarez Espada y su familia.

Como consecuencia de ese acuerdo se encargó a los profesores de cada una de esas unidades docentes que presentaran propuesta de distribución de lo que correspondía a cada una de ellas, incluyendo los correspondientes laboratorios de prácticas. Las Propuestas y la distribución de la planta baja del edificio A se estudiaron y aprobaron en la sesión de la Junta del 4 de julio de 1978.

También se hizo patente que no era posible levantar un edificio tan complejo como era el platillo volante con el presupuesto existente, que se había quedado obsoleto. Se planteó un reformado de obra que incluyera los cambios acordados en los módulos A y B y sustituir el aulario proyectado (Fig. 2b1) por un edificio de aspecto exterior semejante a esos dos módulos, ubicado en la reserva de espacio en línea con el módulo A, que permitiría colocar seis aulas de buen tamaño, tres más grandes que las otras, situadas éstas en la proximidad de la escalera (Fig. 2b2). Del proyecto del reformado se encargó el arquitecto D. Luis Ameijide Montenegro, de la Unidad Técnica de León de la Junta de Construcciones, Instalaciones y Equipo Escolar, quien fue el arquitecto director de obra, con D. Luis Roy Ramos como Arquitecto Técnico. Con el reformado el edificio tendría una superficie útil de $4.800 \mathrm{~m}^{2}$.

A finales de noviembre se comunicó desde el Rectorado de Oviedo que se había aprobado el reformado del proyecto, pero no así la ampliación del edificio, indicando estar haciendo todo lo posible para lograrlo20. La aprobación del reformado se complicó mucho más de lo esperado -las modificaciones sobre el proyecto inicial eran muy sustanciales, aunque estaban muy bien justificadas $-\mathrm{y}$ hasta septiembre de 1981 no quedó autorizada la finalización del edificio ${ }^{21}$. No obstante, a finales del mes de julio de 1979 se había celebrado en Oviedo la subasta del amueblamiento del edificio y las empresas adjudicatarias procedieron con rapidez.

Ya finalizado el edificio y adjudicado el mobiliario de despachos, bibliotecas y laboratorios, el catedrático de Microbiología Dr. Martín Martín pidió que se trasladasen al nuevo edificio todos los departamentos. Se desechó la idea ${ }^{22}$, pero Microbiología acabó trasladándose a los espacios que algunos departamentos de la Facultad habían dejado libres en la Escuela de Ingeniería Técnica Agrícola, contradiciendo uno de los criterios básicos de la distribución de espacios,

\footnotetext{
20 Libro de Actas II de la Junta de Facultad, sesión del 21 de noviembre de 1978, página 11 vuelta.

21 Libro de Actas II de la Junta de Facultad, sesión del 6 de octubre de 1978, página 96 cara.

22 Libro de Actas II de la Junta de Facultad, sesión del 30 de marzo de 1982, páginas 133 vuelta y 134 cara.
} 
cuál era el de disminuir el número de locales ocupados.

El 26 de abril de 1982, festividad de San Isidoro, fue inaugurado el edificio por el Subsecretario del Ministerio de Educación y Ciencia Excmo. Sr. D. Antonio Lago Carballo, siendo Ministro de Educación y Ciencia el Excmo. Sr. Dr. D. Federico Mayor Zaragoza, siendo Presidente de la Comisión Gestora de la Universidad D. José Luis Sotillo Ramos - catedrático de Producción Animal de la Facultad de Veterinaria - y Decano de la Facultad el Prof. Nieto Nafría (Figs. 5, 6 y 7).

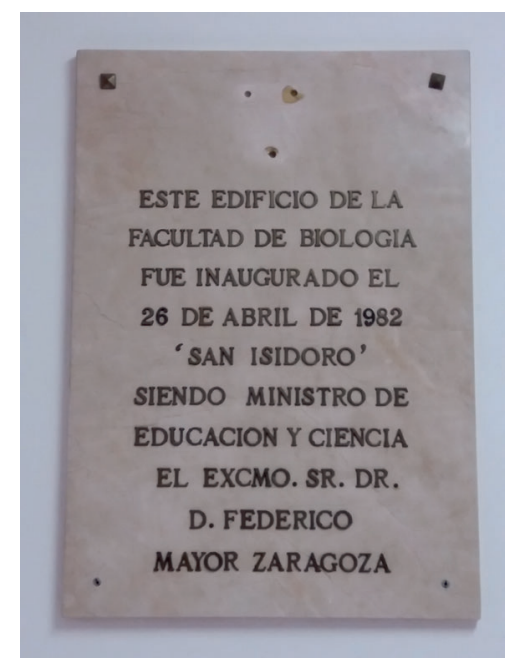

Figura 5. Placa conmemorativa de la inauguración de la primera fase del edificio Central de la Facultad.
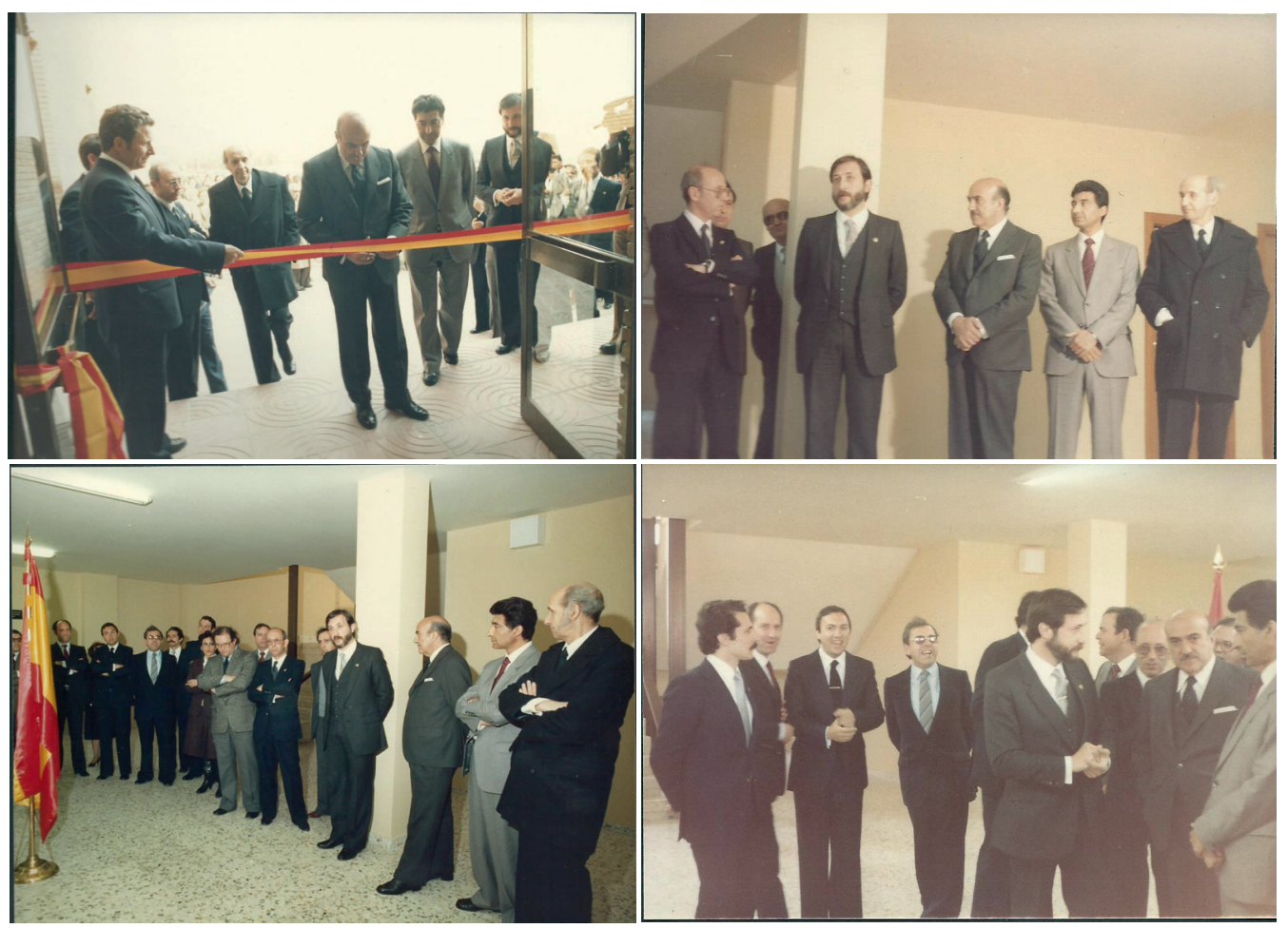

Figura 6. Diversas instantáneas del día de la inauguración de la primera fase del edificio, donde se ve el ritual de corta de la cinta por el representante del Ministerio y la participación de las autoridades académicas de la Universidad de León y de la Facultad de Biología (fotografías del archivo de la Universidad de León). 
De inmediato se procedió al traslado de enseres desde los locales que se habían estado ocupando durante años y en la Junta del 5 de mayo se acordó que «se consideraran como lugares autorizados para fumar los vestíbulos, corredores y pasillos y las aulas en exámenes con la condición, en éste último caso, de autolimpieza» 23 , no entrando en consideración de lo que se pudiera hacer en los despachos de los profesores. Bastantes años más tarde, en la Junta del 21 de diciembre de 2004 surge de nuevo el tema del tabaco, sobre el asesoramiento acerca de la regulación de su uso en la Facultad, de acuerdo con el artículo 89h del Estatuto de la Universidad, y en la que se acordó señalar tres puntos para fumadores, prohibiéndose en el resto de dependencias con competencia del decanato, sin concretar nada sobre los espacios departamentales.

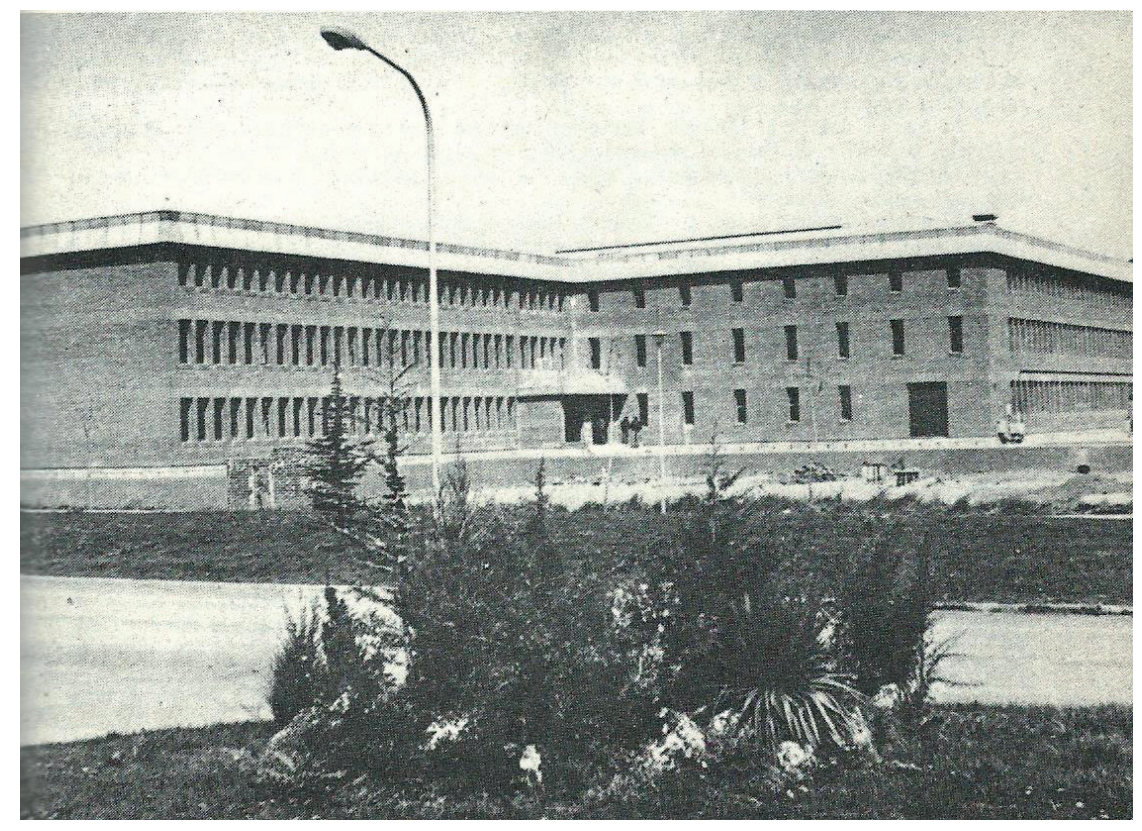

Figura 7. Vista de la primera fase del edificio en 1982 (Tomada de Cordero del Campillo, 1983:429).

\section{La segunda fase del edificio}

La petición de una ampliación del edificio había sido una constante desde el mismo momento de saberse en qué consistía el edificio proyectado $a b$ initio para la Facultad, máxime sabiendo que el redactor del proyecto y quienes lo habían autorizado habían consignado dos espacios para construir una ampliación; uno de esos espacios ocupado ya por el módulo de aulas del reformado, módulo $\mathrm{R}$.

La ampliación había contado con el cerrado apoyo de la Comisión Gestora de la Universidad de León desde el mismo momento de su constitución a raíz de la aprobación de la Ley de creación de la Universidad de León, presidida por el

23 Libro de Actas II de la Junta de Facultad, página 135 vuelta. 
Dr. Sotillo Ramos y de cuya Comisión Permanente inicial habían formado parte los doctores Cadenas Bergua, como Vicepresidente para la Investigación, y Nieto Nafría, primero como Secretario General de la Universidad y después sucediendo al Dr. Cadenas cuando éste dejó el cargo por traslado a la Universidad de Alicante.

No hubo discusión en lo que convenía levantar, un módulo semejante a los A y B, paralelo a ellos, en el espacio ya consignado en el proyecto de la primera fase, que podemos llamar $\mathrm{C}$, un módulo semejante alineado con este último y de un tamaño semejante al módulo $\mathrm{R}$, que podemos llamar $\mathrm{D}$, también para departamentos, y un módulo que uniese ésta con el R, de dedicación diversa, que podemos llamar F, cuya fachada habría de ser la fachada principal del edificio. Entre los módulos F, D y R y el corredor de conexión de los módulos A y C quedaría un amplio patio interior ajardinado (Fig. 2c).

Iniciadas las obras de la segunda fase, y como consecuencia de que la entrada principal quedaría solamente para acceso al futuro patio interior, se abrió la puerta de la fachada este del edificio con acceso a la explanada central del campus, reduciendo el aula de la planta baja más próxima a las escaleras.

En la sesión de la Junta de Facultad del 12 de mayo de 1980 -idos años antes de la inauguración de la primera fase! - se trató de la «Distribución de espacios en la ampliación de la Facultad» y se aprobó por unanimidad el plan de presentado por el Prof. Nieto, que incluía la modificación de la distribución de las plantas primera y segunda del módulo A y en parte la planta baja de ese módu$\mathrm{lo}^{24}$. Esa distribución hubo de variarse debido a los cambios habidos en la dotación de la plantilla docente y en el plan de estudios y ya en el tiempo de redacción del proyecto debido a la negativa del Ministerio a que el módulo F tuviera tres plantas, porque no lo justificaba el número de alumnos matriculados.

Así en la Junta del 17 de marzo de 1982 se trató de la «Reestructuración, si ha lugar, de espacios en la segunda fase del edificio de Biología» y se tomaron los siguientes acuerdos: 1) adjudicar a Morfología Microscópica la primera planta completa del llamado A, y pasar Antropología - con parte del profesorado que había sido de Biología General- a la planta baja del módulo C, ubicaciones que más adelante se intercambiaron; 2) adjudicar a Ecología la entera planta segunda del módulo A; 3 ) adjudicar las plantas primera y segunda del módulo $\mathrm{C}$ respectivamente a Microbiología y a Genética; 4) adjudicar las plantas baja, primera y segunda del módulo D respectivamente a Fisiología Vegetal, a Fisiología Animal junto con Física y a Bioquímica para Química; 5) adjudicar a Geología la segunda planta del módulo R, en el lugar ocupado hasta ese momento por dos au-

24 Libro de Actas II de la Junta de Facultad, páginas 61 cara a 62 cara. 
las, debido a que la primera planta del módulo $\mathrm{F}$ se dedicaría íntegramente a aulas. Todo ello en el entendido de que tanto desde Física como desde Química habría que atender a estudiantes de Veterinaria, de la misma forma que desde dependencias de Bioquímica y también de Fisiología Animal en el nuevo edificio de Veterinaria se atendería a los estudiantes de la Facultad 25.

El proyecto lo elaboró el arquitecto D. Miguel Martín-Granizo Casado. En su inicio se preveía una pequeña cafetería en el ángulo sureste del edificio, pero como ya estaba avanzada la obra del primer módulo del edificio de servicios de la Universidad en el campus, planteado para esa función y de uso general, desde el decanato - siendo decano y secretario los firmantes- se propuso modificar toda la zona este de la primera planta y destinarla a cubrir las actividades de conserjería, la sección de administración y secretaría y la dirección de la Facultad. Sobre un boceto del Prof. Luis Calabuig -Secretario de la Facultad - el arquitecto mejoró el diseño y optimizo los espacios en el proyecto definitivo (Fig. 8), dedicando los espacios que anteriormente ocupaban esos servicios en la planta baja del módulo A de la primera fase para el herbario y la sala de colecciones zoológicas. Finalmente la superficie útil era de $527 \mathrm{~m}^{2}$ y el presupuesto de edificación ascendía a 142 millones de pesetas. La obra se le adjudicó por concurso a la constructora Sastrón y Cía S.A. en julio de 1983, figurando en el BOE con el número de orden 80, como Ampliación de la Facultad de Biología de León ${ }^{26}$.

Figura 8. En el ángulo sureste del proyecto de la segunda fase de construcción del edificio, realizado por el arquitecto Miguel Martín-Granizo, estaba diseñada la ubicación de un bar (a). Desde la Facultad se sugirió una modificación para colocar en esa misma posición el decanato y la sección administrativa de secretaría, sobre un boceto del Dr. Luis, entonces Secretario de la Facultad (b), que fue asumido y mejorado en el proyecto final (c).

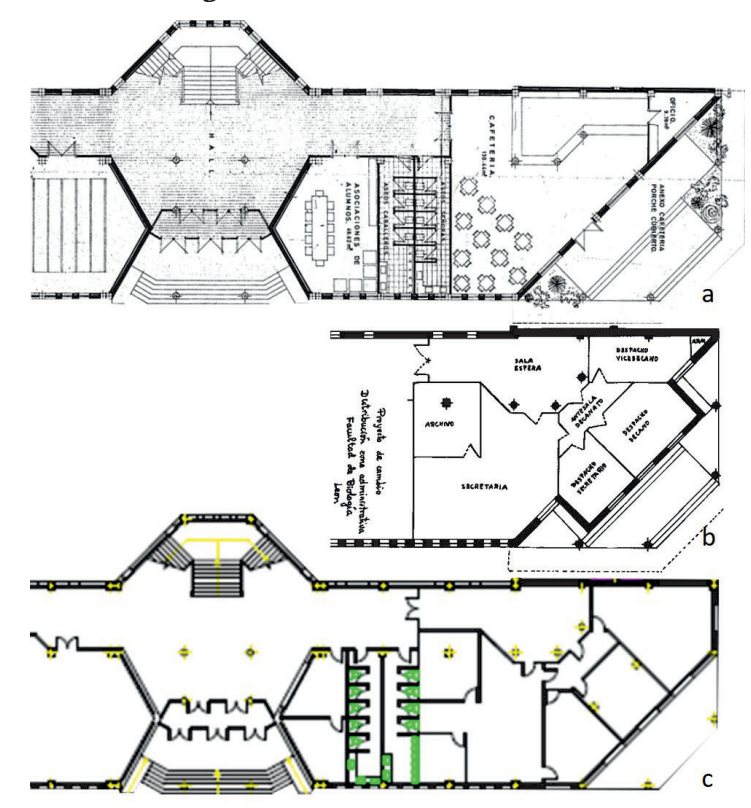

25 Libro de Actas II de la Junta de Facultad, páginas 130 cara a 133 vuelta.

26 Boletín Oficial del Estado, 1987 num. 139:17652, de 11 de junio, en el informe de 12 de febrero, del Pleno del Tribunal de Cuentas, elevado a las Cortes Generales, relativo a la fiscalización selectiva realizada al Organismo Autónomo «Junta de Construcciones, Instalaciones y Equipo Escolar», en base a las cuentas rendidas de los años 1981, 1982 y 1983. 
La fachada principal lucía un aspecto totalmente diferente al resto de lo ya construido y cambió completamente la fisonomía del edificio. En 1993 se propuso como logotipo durante la conmemoración del 25 aniversario del inicio de la Facultad de Biología ${ }^{27}$ y, pasados los años, como cierre de portada de la revista Ambiociencias (Figs. 9 y 10).

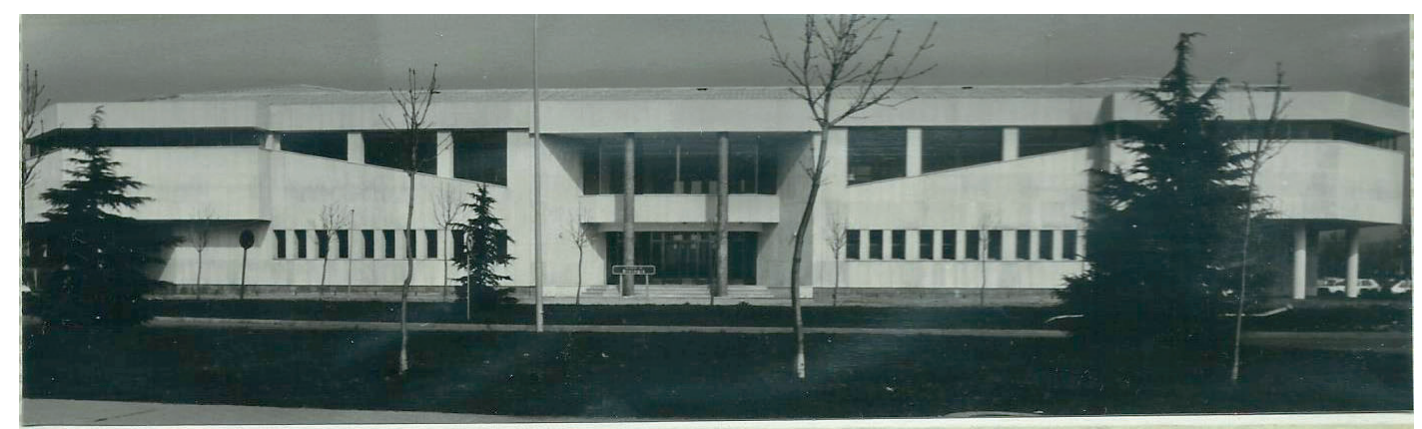

Figura 9. Fachada principal del edificio poco después de su finalización en 1985 (fotografía del archivo de la Universidad de León).

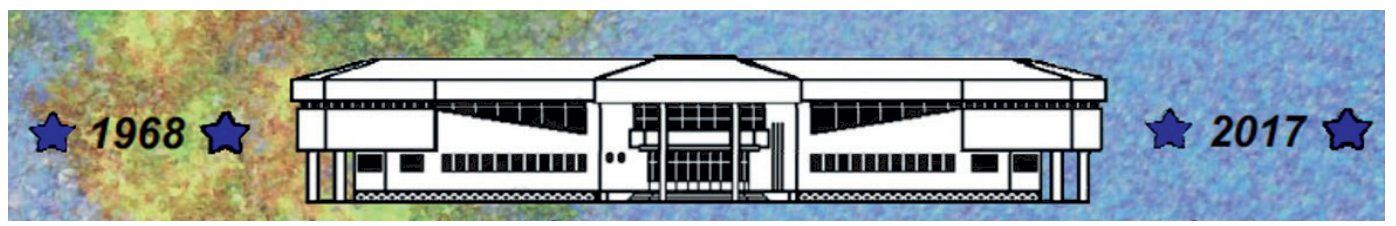

Figura 10. El dibujo realizado por el Prof. Luis Calabuig, basado en la fachada principal del edificio, fue adoptado como logotipo oficial del $25^{\circ}$ aniversario de la Facultad de Biología y, posteriormente, como cierre de portada de la revista Ambiociencias.

La acordada distribución para departamentos se alteró por diversos problemas de organización docente que afectó a los profesores de Geología, Paleontología y Edafología, de tal modo que Geología pasó a ocupar media planta primera del módulo $\mathrm{D}$, con entrada desde el módulo $\mathrm{F}$, quedando la otra media planta - con acceso desde el distribuidor entre $\mathrm{Cy} \mathrm{D}$ - para Física y como reserva ante necesidades futuras, y la segunda planta del módulo F para Física. Definitivamente Bioquímica y Fisiología Animal quedaban en Veterinaria, cuyo nuevo edificio ocupaba ya un lugar en el campus en la vecindad del de Biología (Fig. 11).

Esta segunda fase del edificio se inauguró el 8 de mayo de 1985, día en el que se celebraba la festividad de San Isidoro, siendo entonces Ministro de Educación y Ciencia el Excmo. Sr. D. José María Maravall Herrero, siendo Rector Magnífico de la Universidad el Prof. Cordero del Campillo, y Decano el Prof. Nieto Nafría (Fig. 12).

27 Libro de Actas IV dela Junta de Facultad, folio oC2200098. 
Figura 11. Emplazamiento de la primera fase del edificio de Biología en el campus en su último tramo de construcción, con el edificio del antiguo Colegio Universitario hacia el oeste y la Facultad de Veterinaria en construcción hacia el norte (Tomada de Cordero del Campillo, 1983:429).

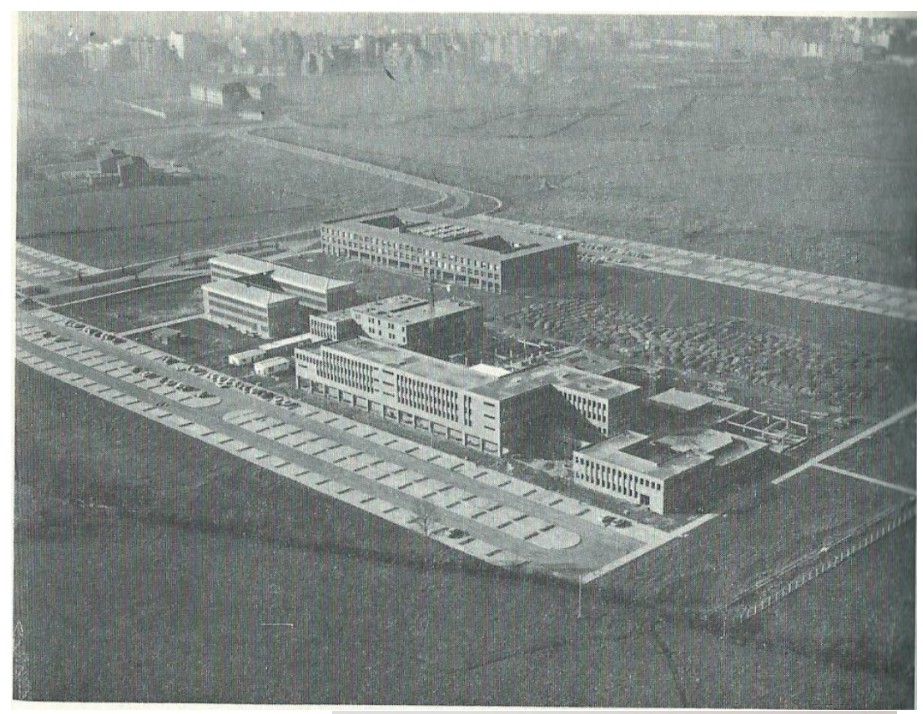

Figura 12. Placa conmemorativa de la inauguración de la segunda fase del edificio.

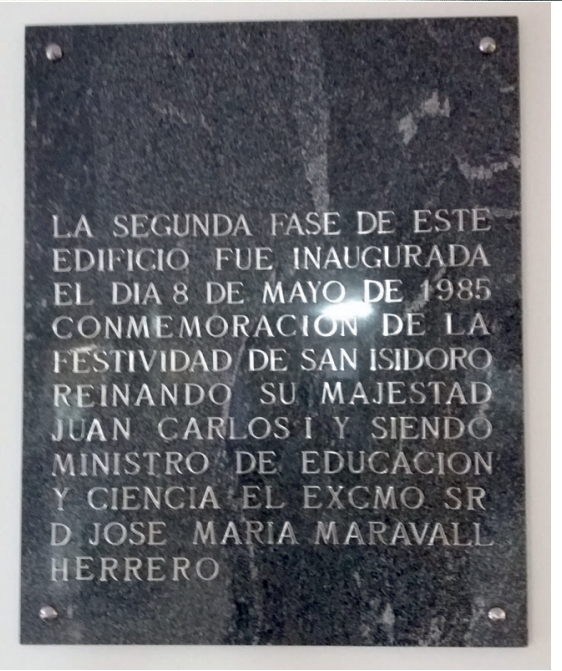

En años sucesivos se toman algunas decisiones sobre el edificio, como el uso de llave y tarjeta para poder acceder al edificio por la puerta lateral este durante la noche, fines de semana y festivos, tratado en noviembre de $1989^{28}$, o la colocación de un ascensor, tratado en octubre de $1991^{29}$. La segunda fase contaba en un principio con un sistema de poleas, cuyo soporte superior aún permanece, que fue sustituido por un montacargas exterior con entrada al pasillo de conexión entre los módulos $\mathrm{B}$ y $\mathrm{C}$, mucho más eficaz en el proceso de amueblamiento del edificio, en el que no estaba permitido el uso para personas. La necesidad del ascensor surgió algo más tarde para cumplir con la eliminación de las barreras arquitectónicas, y fue colocado enfrente del montacargas con montaje en el patio interior y cabina acristalada que daba vista al recinto ajardinado.

En 1993, con motivo del vigesimoquinto aniversario del inicio de los estudios de Biología en León, empezó a gestarse la posibilidad de colocar una vidriera 
alusiva al mundo de la Biología, en la escalera principal. La obra titulada "Materia, movimiento y vida" fue realizada por Fernando Vicent del Campo, firmada con el pseudónimo de Algú en 1993 y terminada en enero de 1994 . Consta de 20 paneles construidos mediante la técnica de montaje de cobre estañado, utilizando como material básico el vidrio soplado, con dominio de colores en azul cobalto, rojos cobre y selenio, y rosas de oro, así como los vidrios soplados en masa de colores verdes que representan en parte a la flora, y los amarillos y naranjas más corpóreos y opacos, que simbolizan la tierra. Los 12 centrales (Figura 13) 30 describen la escena principal en torno a la doble hélice del ADN, y los dos grupos laterales están dedicados a la vegetación y a la fauna, respectivamente.

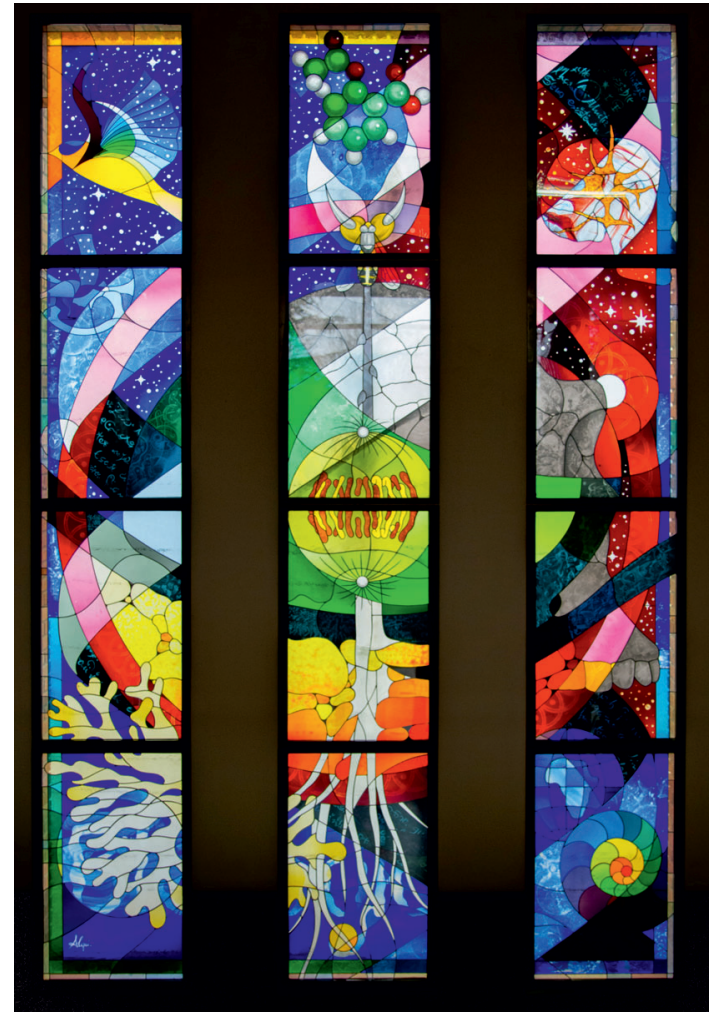

Figura 13. Paneles centrales de la vidriera de la escalinata principal del edificio (fotografía de Daniel de Luis).

En 1995, ante los problemas que se suscitaron al utilizar los altillos del edificio como almacén, y tratando de evitar posibles riesgos, se planteó añadir una planta con el doble objetivo de mejorar la habitabilidad de lo que hasta entonces era una simple cámara de aislamiento, reformando la estructura y reforzando el techado. En la Unidad Técnica de la Universidad, a cargo del arquitecto técnico Sr. Roy Ramos, se elaboró un anteproyecto que valoraba la actuación en algo más de 35 millones de pesetas (Fig. 14). Finalmente la idea se desestimó fundamentalmente por cuestiones económicas. En época más reciente se abordó el tema de aislamiento del tejado para dar solución a los riesgos por almacenamiento en los

3025 aniversario de la facultad de Biología. Secretariado de Publicaciones. Universidad de León, 1995:279. 


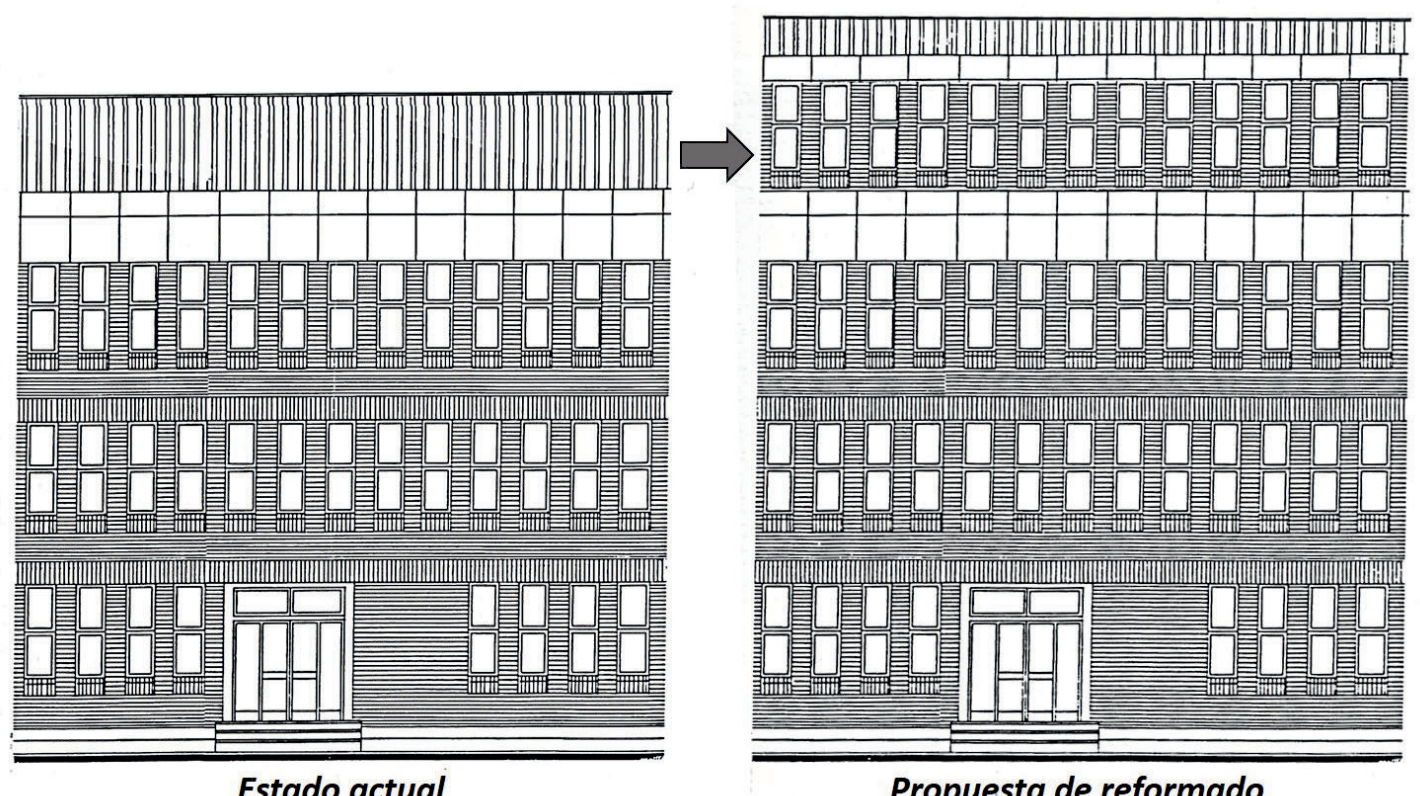

Figura 14. Propuesta de modificación del edificio, añadiendo una cuarta planta (diseño del arquitecto técnico Sr. Roy Ramos).

desvanes realizando una obra de compartimentación, reforzado y aislamiento. Posteriormente (2015) se repararon las cubiertas, retirando las placas de fibrocemento y construyendo un nuevo sistema de cubierta, formado por un panel nervado de cubierta de dos chapas de acero prelacadas con núcleo de aislamiento de espuma de poliuretano colocado sobre la estructura existente, que mejoraba el aislamiento térmico y la impermeabilidad. La obra fue realizada por la empresa Obras y Pavimentaciones Hidráulicas, S.L., siendo autor del proyecto el arquitecto técnico D. Julio Macías Rubio.

Aunque el edificio ya estaba funcionando, tanto para las clases teóricas como las prácticas, la urbanización del entorno se retrasó algunos años, hasta que quedó definida la explanada central del campus, dando con ello fin a la vereda de tierra, coloquialmente conocida como "senda de los elefantes", que unía la entonces parte oeste del edificio con los servicios centrales de la Universidad que ocupaban parte del antiguo edificio del Colegio Universitario - actual Facultad de Filosofía y Letras - y el bar, que fue sustituido en 1986 por la cafetería central (Figs. 15y 16).

En 1989 en el espacio ajardinado de la fachada principal de la facultad se colocó una escultura del autor Juan Carlos Uriarte, conocido en el mundo artístico como Johnny, titulada "Johnnysaurius legionensis", construida con piezas de hierro de desecho industrial que, organizadas por el artista con libertad e imaginación, recuerda a los restos óseos de un gran dinosauro (Fig. 17). 

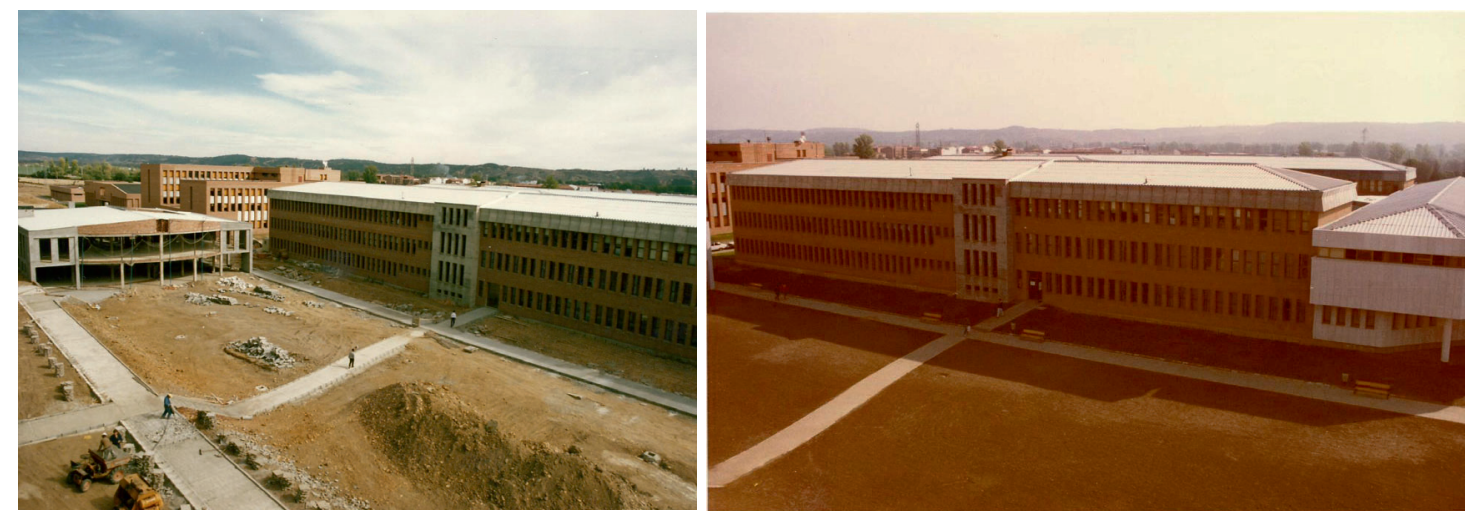

Figura 15. Dos momentos de la urbanización del entorno oeste de la Facultad en 1985 (fotografías del archivo de la Universidad de León).

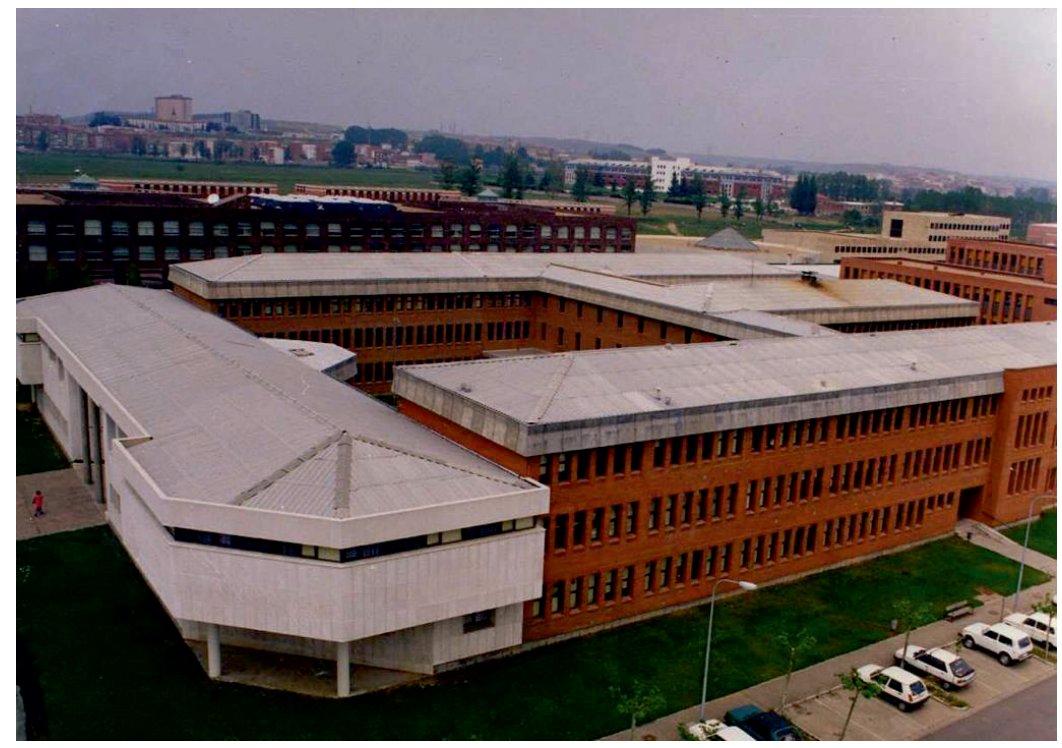

Figura 16. Vista aérea del edificio de la Facultad completada la segunda fase de construcción y urbanización (fotografía del archivo de la Universidad de León).
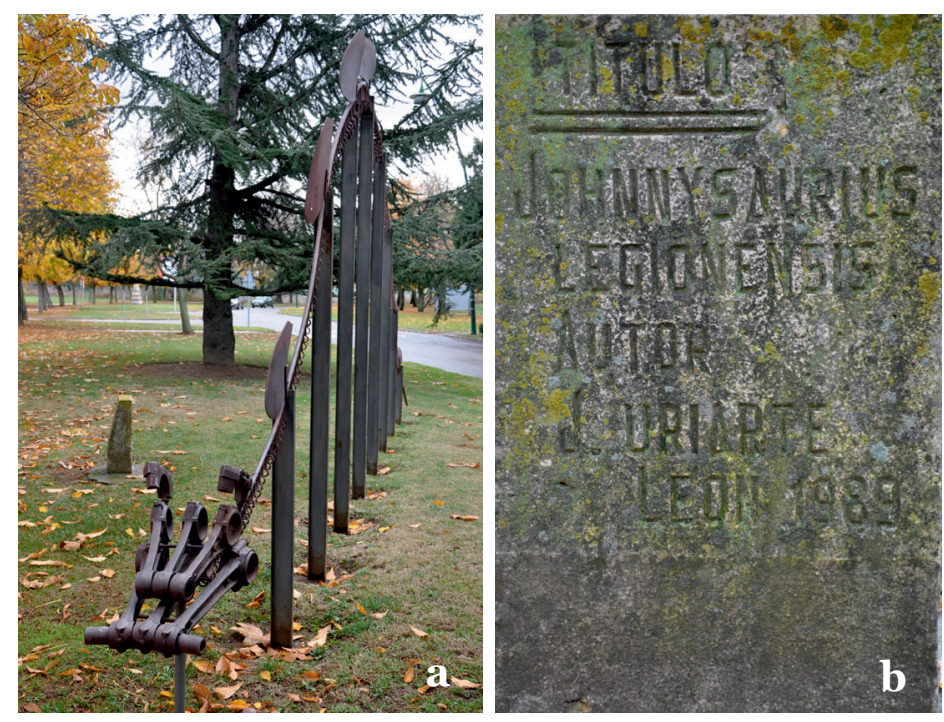

Figura 17. Escultura del autor J. C. Uriarte colocada en 1989 frente a la fachada principal de la facultad (a) y titulada "Johnnysaurius legionensis"(b). 


\section{La tercera fase del edificio}

En 1996, vuelve a plantearse de nuevo el problema de la escasez de espacios para impartir de forma eficiente toda la docencia teórica y práctica, haciendo llegar al Rector, desde el decanato de la Facultad, ostentado entonces por la Dr. ${ }^{\mathrm{a}}$

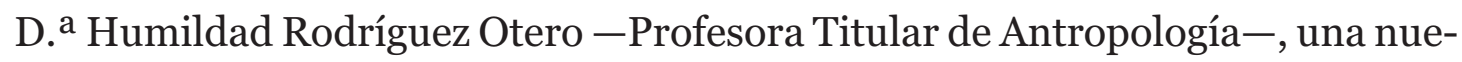
va propuesta de ampliación del edificio ${ }^{31}$. Se partía de un análisis previo realizado por D. Luis Roy desde la Oficina Técnica de la Universidad, en el que se consideraba la posibilidad de edificar tres plantas ocupando parte del patio interior del edificio, con espacios para aulas y laboratorios de prácticas. En la Junta de Facultad de los días 27 de junio ${ }^{32}$ y 7 de noviembre de $1996^{33}$, se trató de la ampliación de espacios para la Facultad, presentándose una propuesta por una comisión delegada nombrada al efecto, y aprobándose que constaría de cuatro aulas y cuatro laboratorios de prácticas, de acuerdo con el proyecto diseñado por la Unidad Técnica de la Universidad, evitando así que algunas asignaturas tuvieran que impartirse fuera de la Facultad.

El proyecto definitivo de esta fase es de agosto de 1997 (Fig. 2d) y está fir-

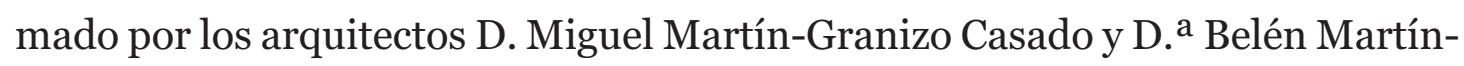
Granizo López. En $1.780 \mathrm{~m}^{2}$ útiles se ubicaban: en la planta baja el aula magna en posición transversal al pasillo de conexión de los módulos A, B y C (Figs. 18a y 18b), y dos aulas en posición longitudinal a ambos lados de la anterior; en la primera planta dos laboratorios de prácticas y un aula grande central y dos pequeños despachos; en la segunda planta una amplia biblioteca en dos alturas (Fig. 19) y un habitáculo para servicios por el que podía accederse al ático del módulo central en el que se colocaría un invernadero (Fig. 2o) a compartir por varios
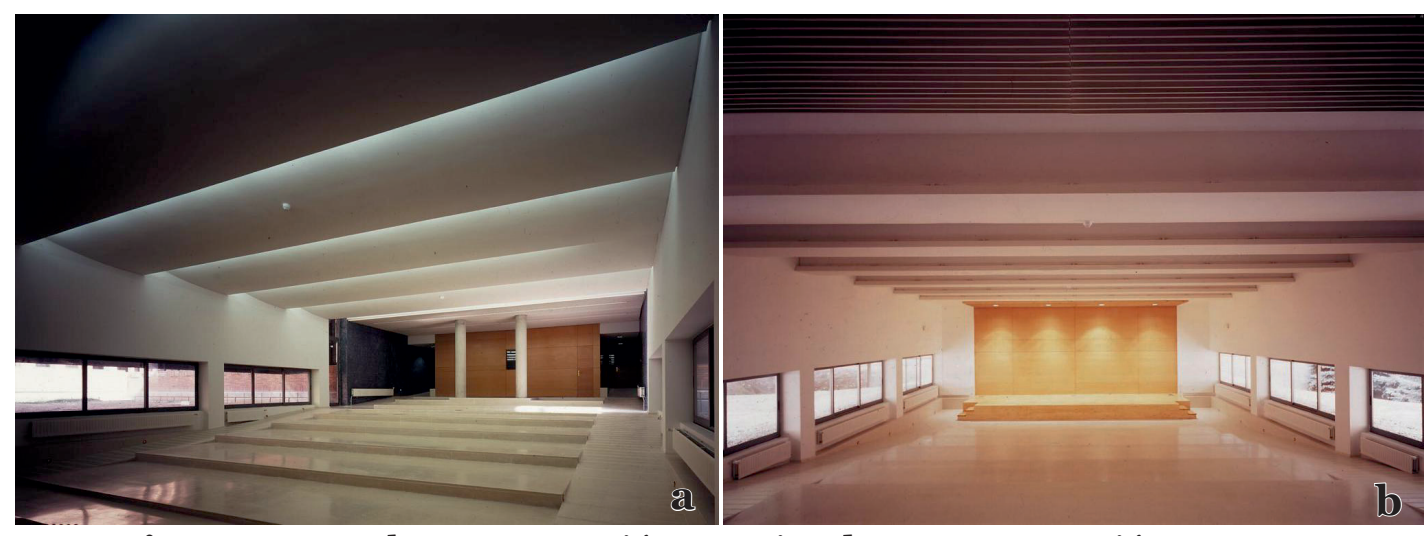

Figura 18. Aula Magna recién terminada su construcción y antes del amueblamiento. Entrada trasera (a) y escenario (b) (fotografías del archivo de la Universidad de León).

31 Comunicación interna número 210696.1.

32 Libro de Actas IV de la Junta de Facultad, folio oC2200127.

33 Libro de Actas IV de la Junta de Facultad, folio oC2200130. 


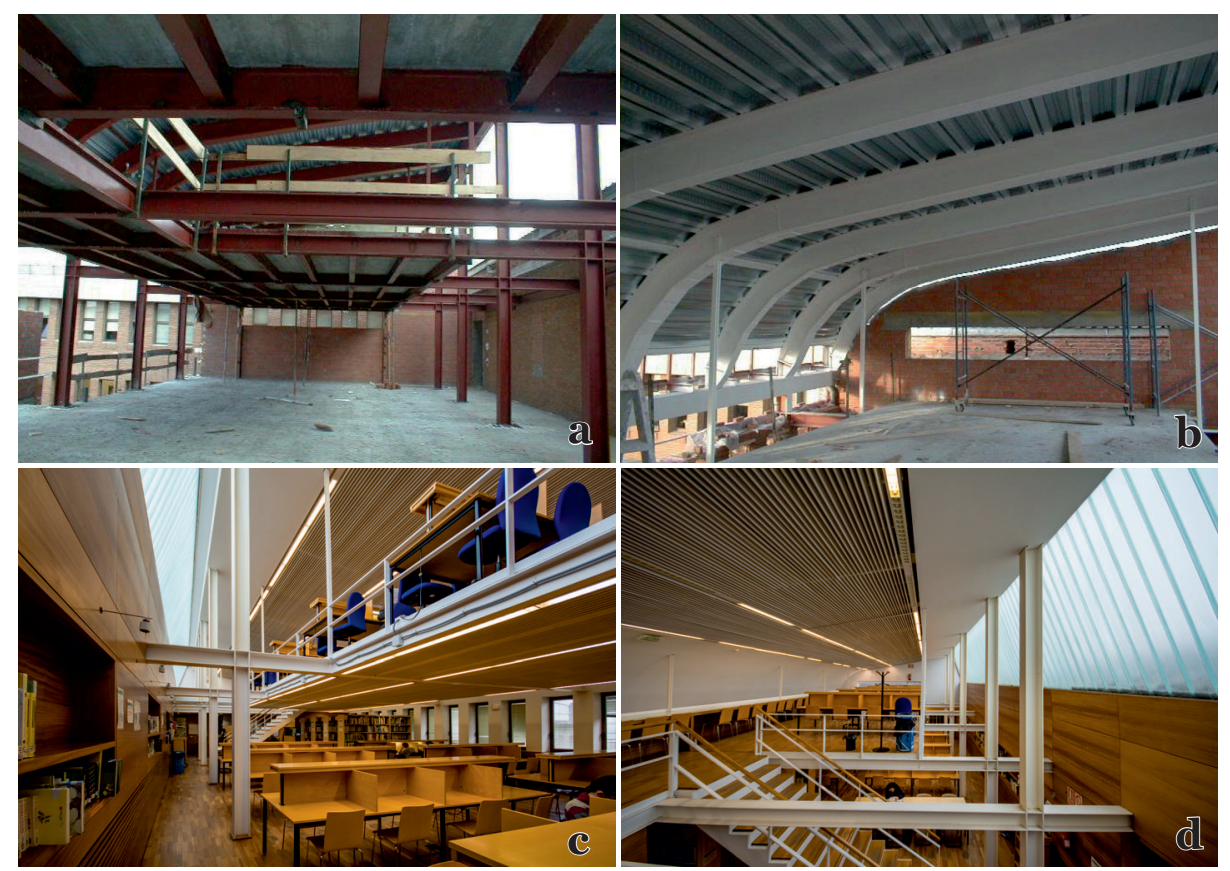

Figura 19. Espacio actual de las dos plantas de la Biblioteca de la Facultad en sus fases de construcción (a y b) -fotografías del archivo de la Universidad de León- y en funcionamiento (c y d) fotografías de Daniel de Luis-.

grupos de investigación, atendiendo a la petición del Dr. Pérez de la Vega, al invadirse el espacio ocupado por el anterior invernadero. Los paños del módulo longitudinal de esta ampliación seguían el diseño de ventanales estrechos y ladrillo cara vista, mientras que el transversal se cerraba con planchas claras, fundamentalmente para dar más luminosidad a la vidriera de la escalinata principal del edificio (Fig. 21). Este módulo envolvió el hueco del ascensor, cuyas cristaleras fueron selladas con paneles.
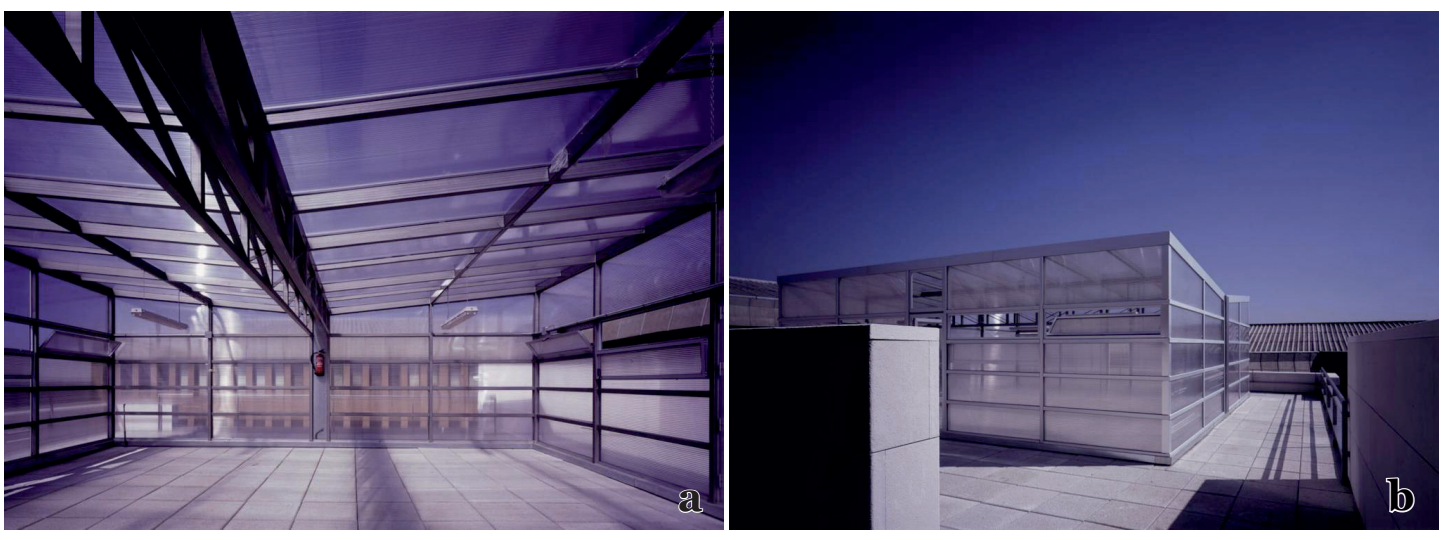

Figura 2o. Vistas interior (a) y exterior (b) del invernadero, recién terminada su colocación en el ático del módulo de la tercera fase (fotografías del archivo de la Universidad de León). 

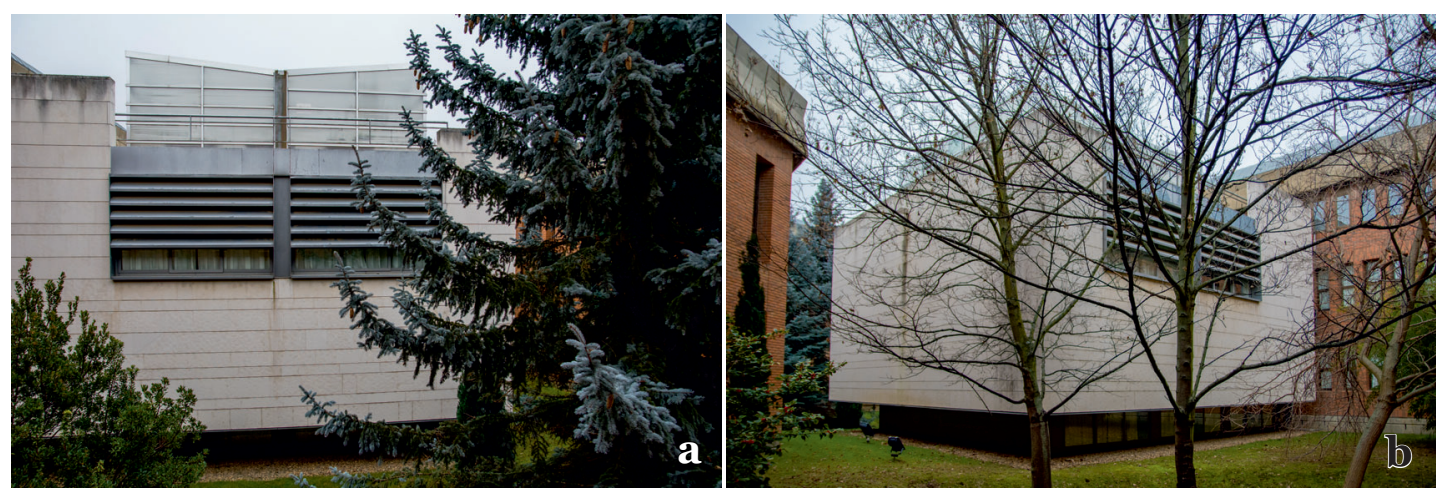

Figura 21. Vista de los módulos construidos en la tercera fase en el patio interior de la Facultad (fotografías de Daniel de Luis).

El presupuesto de la construcción ascendía a 178,1 millones de pesetas. La obra la realizó ACS Construcciones. El Acta de Comprobación del Replanteo está firmada el 5 de marzo de $1998^{34}$, por lo que la obra se inició al día siguiente, una vez que varios de los árboles existentes en la parte del patio que se iba a ocupar se trasplantaran a la zona ajardinada inmediata a la fachada occidental del modelo $\mathrm{C}$ del edificio.

El Excmo. Sr. Presidente de la Junta de Castilla y León, D. Juan José Lucas Giménez, inauguró esta tercera fase del edificio el 19 de noviembre de 1999, siendo Rector Magnífico D. Julio César. Santoyo Mediavilla - catedrático de Tra-

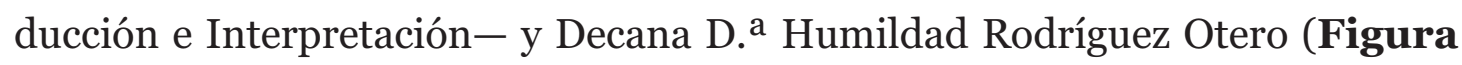
22).

Figura 22. Placa conmemorativa de la inauguración de la tercera fase del edificio de la Facultad.

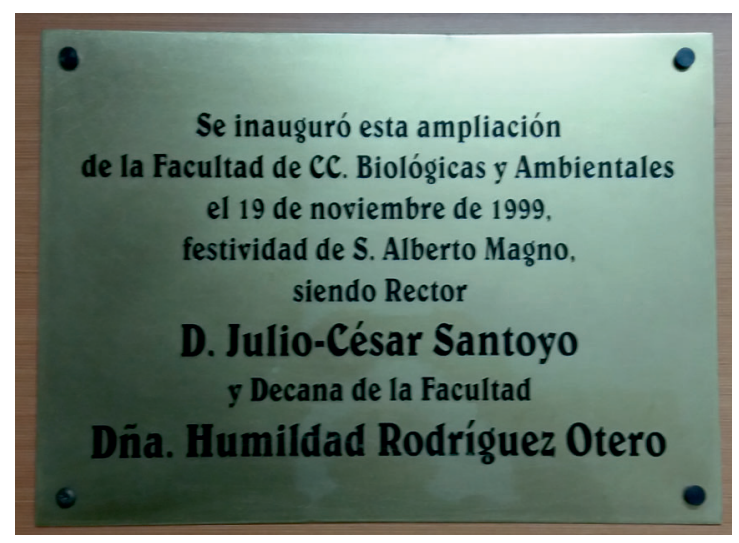

\section{El edificio Darwin}

Como consecuencia del aumento de titulaciones que se impartían en la Facultad, de Biología, de Ciencias Ambientales y de Biotecnología, con el consiguiente aumento del número de estudiantes, las dificultades para organizar ho-

34 Documento de seguimiento de obra archivado en la Oficina Técnica de la Universidad de León. 
rarios, la ocupación de espacios y las actividades docentes de los profesores, se estimaba que era necesario aumentar los espacios dedicados a la docencia. Demandas de aumento que se extendían a varios departamentos. Por iniciativa del Rector Magnífico Dr. D. Ángel Penas Merino - catedrático de Botánica-, secundado por el Decano Dr. D. José Carlos Pena Álvarez - profesor titular de Zoología - se realizó un sondeo, y el sumatorio de las demandas superaba con mucho la cantidad que la Junta de Castilla y León podía dedicar a ese fin, 4,5 millones de euros, que procedía de fondos FEDER.

Como levantar un edificio departamental requería más dinero por unidad de superficie, por el coste de las infraestructuras requeridas, tras debates en la Facultad y de acuerdo con la Junta, se decidió que el nuevo edificio tuviera carácter docente y que una vez puesto en marcha se remodelasen los espacios que se desocuparan en el edificio existente.

El 20 de diciembre de 2005 se anuncia que es inminente la convocatoria del concurso de presentación de proyectos para el nuevo edificio, solicitando precisión en cuanto a las necesidades y sugiriendo que sería conveniente diseñar dos módulos diferentes para aulas y laboratorios ${ }^{35}$. La Universidad presentó una propuesta de actuación concreta, en cuya preparación intervino, además del Sr. Decano, el entonces Vicerrector de Inversiones e Infraestructuras Dr. D. José Luis Placer Galán -catedrático de Comercialización e Investigación de mercados-y los equipos directivos de los departamentos se aplicaron en la redacción de memorandos que pusieran de manifiesto sus necesidades y sus propuestas de utilización de los espacios que estaba previsto desocupar.

$\mathrm{El} 3$ de marzo de 2006 se informa que han sido presentados 7 proyectos y se adelanta como posible calendario que, una vez adjudicado, se dispondría de 4 meses para la presentación del proyecto final, que entre octubre y noviembre se haría la licitación de obra y que debería ejecutarse en ${ }^{18-20}$ meses $^{36}$. El 6 de abril se informa sobre la adjudicación del proyecto, la trasmisión de necesidades y la presentación de planos ${ }^{37}$. Las obras se inician en enero de $2007^{38}$, de la que se va informando sobre el estado de su construcción de forma regular ${ }^{39}$. El 8 de noviembre de 2007 se señala que la fecha de entrega se prevé para mayo de 2008 , se plantea como problema la estrechez de escaleras y pasillos ${ }^{40}$ y se comienza a tratar el tema del mobiliario que fue organizado por el Decanato de la Facultad y la Gerencia de la Universidad. Concretamente la oferta de mobiliario de laborato-

\footnotetext{
35 Libro de Actas V de la Junta de Facultad, folio oD4744285 cara.

36 Libro de Actas V de la Junta de Facultad, folio oD4744289 vuelta.

37 Libro de Actas V de la Junta de Facultad, folio oD4744292 vuelta.

38 Libro de Actas V de la Junta de Facultad, folio oD4744297 vuelta.

39 Libro de Actas V de la Junta de Facultad, folio oD4744300 cara.

40 Libro de Actas V de la Junta de Facultad, folio oD4744304 vuelta.
} 
rio se realiza en diciembre ${ }^{41}$. En Junta de Facultad del 7 de marzo de 2008, y en presencia del Rector, que había sido expresamente invitado, además de tratar sobre modificaciones previstas se anuncia que la entrega sería en el mes de junio ${ }^{42}$, pero para esa fecha se apunta otra dos meses más tarde, cuando ya se ha adjudicado el mobiliario. Por esas fechas las previsiones de remodelación y redistribución de los espacios del edificio central quedan paralizadas desde el rectorado y no se llegó a licitar ${ }^{43}$, quizá como consecuencia del cambio de Rector, en 2008, y de Decano, en 2009, o por el advenimiento de la crisis económica que por entonces empieza a dejar notar sus efectos, aunque posteriormente tal remodelación quedó condicionada a la entrega del nuevo edificio. Finalmente, la falta de fondos para la edificación, para las actividades ordinarias de docencia e investigación de la Universidad y para la reposición de las plazas vacantes por jubilación o por no renovación de contratos hicieron olvidar tales previsiones.

De nuevo, el plazo de entrega no se cumple y en octubre de 2008 se apunta que quizá podría empezarse la docencia en el nuevo edificio para el segundo cuatrimestre ${ }^{44}$. Se insiste en la información que se ofrece el 18 de diciembre en nuevos retrasos para el cierre y entrega ${ }^{45}$, y en marzo de 2009 se informa que la obra está prácticamente terminada ${ }^{46}$, aunque finalmente se concluyó en septiembre de 2009. Concretamente, las actividades docentes en este edificio se iniciaron el día 14 de septiembre ${ }^{47}$, tras su amueblamiento que había comenzado en julio, y la puesta en marcha de los laboratorios por parte del personal técnico dependiente de la Facultad y de los Departamentos, para el que se había contado con un crédito específico de dotación para el edificio y una planificación de adquisición de material para los laboratorios docentes, que se prolongó hasta el mes de noviembre 48 .

El edificio propuesto constaría de tres cuerpos; uno dedicado a laboratorios de prácticas, otro dedicado a aulas y un tercero que uniese los dos anteriores para conserjería, salas de uso diverso y aulas para seminarios (Fig. 2e).

El proyecto lo redactó el arquitecto D. Daniel Díaz Font. El edificio se caracteriza por su revestimiento metálico y por los grandes ventanales de la fechada meridional, la de los laboratorios de prácticas, y de la planta baja de la fachada septentrional, las de las aulas de mayor tamaño (Fig. 23).

\footnotetext{
${ }^{41}$ Libro de Actas V de la Junta de Facultad, folio oD4744307 vuelta.

42 Libro de Actas V de la Junta de Facultad, folio oD4744309 vuelta.

43 Libro de Actas V de la Junta de Facultad, folio oD4744313 vuelta.

44 Libro de Actas V de la Junta de Facultad, folio oD4744316 cara.

45 Libro de Actas V de la Junta de Facultad, folio oD4744318 vuelta.

46 Libro de Actas V de la Junta de Facultad, folio oD4744322 vuelta.

47 Acta electrónica de la Junta de Facultad del día 18 de septiembre de 2009.

48 Acta electrónica de la Junta de Facultad del día 12 de noviembre de 2009.
} 


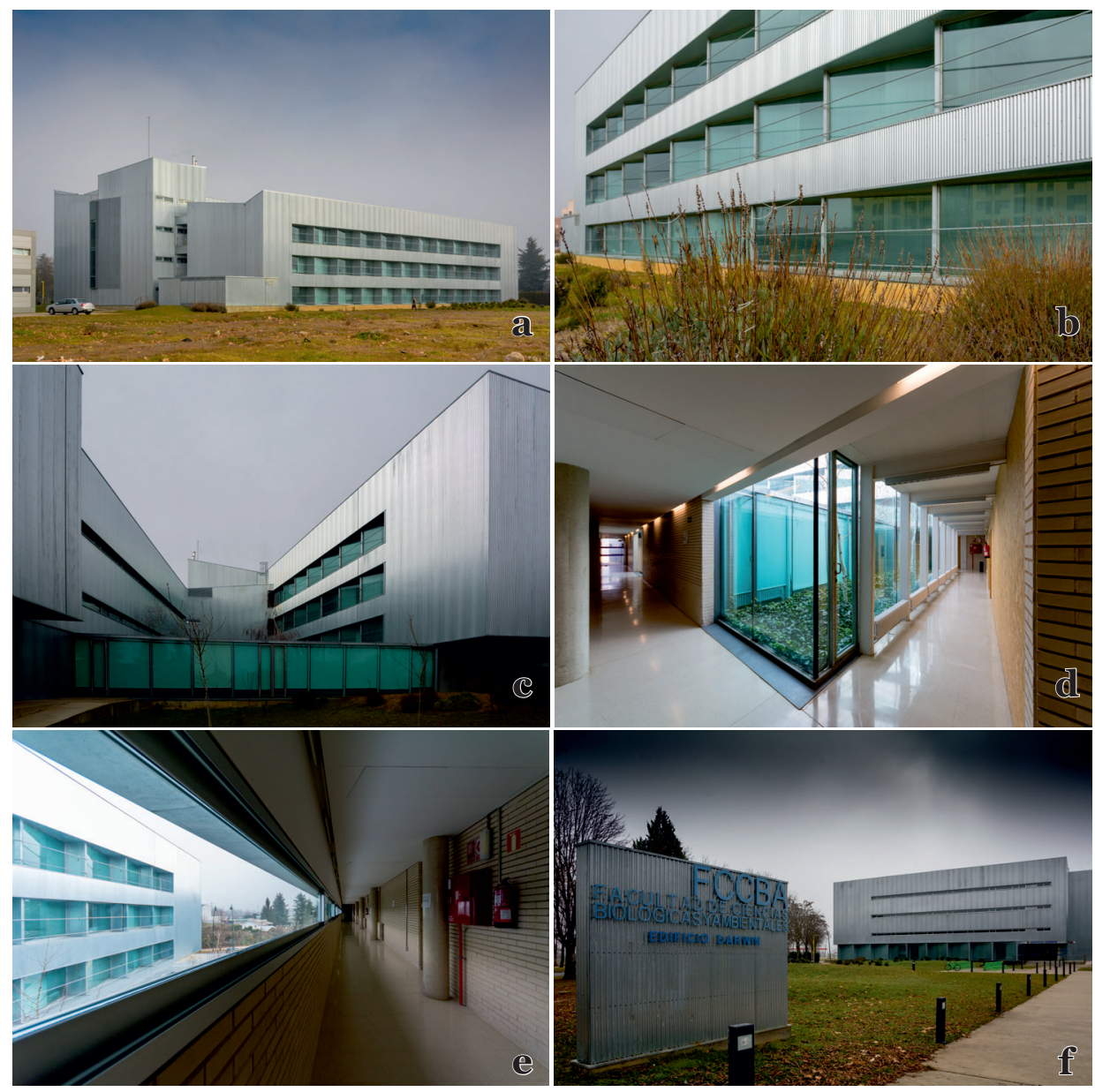

Figura 23. Edificio Darwin de la Facultad de Ciencias Biológicas y Ambientales de la Universidad de León: (a) Vista del edificio desde el ángulo suroeste; (b) Fachada sur del edificio; (c): Las dos alas del edificio desde el este; (d) Pasillos y patio interior en la planta baja; (e) Pasillo de laboratorios en la segunda planta; (f) Fachada principal y entorno urbanizado. Fotografías de Daniel de Luis.

Se levantó con un presupuesto de 4,111 millones de euros. La construcción fue adjudicada por la Dirección General de Infraestructuras y Equipamiento de la Consejería de Educación y Cultura de la Junta de Castilla y León a Ortiz Construcciones y Proyectos.

A propuesta del Sr. Decano, Dr. D. José Carlos Pena Álvarez, Profesor Titular de Zoología, en la conmemoración del bicentenario del nacimiento de Sir Charles Darwin y del sesquicentenario de la publicación de su obra maestra On the Origin of Species by Means of Natural Selection, or the Preservation of Favoured Races in the Struggle for Life, la Junta de Facultad en su sesión del 3 de julio de $2009^{49}$ acordó, por unanimidad elevar al Consejo de Gobierno de la Universidad la propuesta de dar al nuevo edificio el nombre de Edificio Darwin.

49 Acta electrónica de la Junta de Facultad del día 3 de julio de 2009. 
El Darwin fue inaugurado el 21 de diciembre de $2009^{50}$ (Figura 24) por el Excmo. Sr. Presidente de la Junta de Castilla y León D. Juan Vicente Herrera Campo, siendo Rector Magnífico D. José Ángel Hermida Alonso - catedrático de Matemática Aplicada-y Decana D. ${ }^{a}$ Blanca Razquin Peralta - Profesor Titular de Biología Celular-. Fecha extraña para una inauguración en nuestra Universidad, pues las inauguraciones han solido realizarse el día de la fiesta de San Isidoro de Sevilla o el de la apertura de curso.
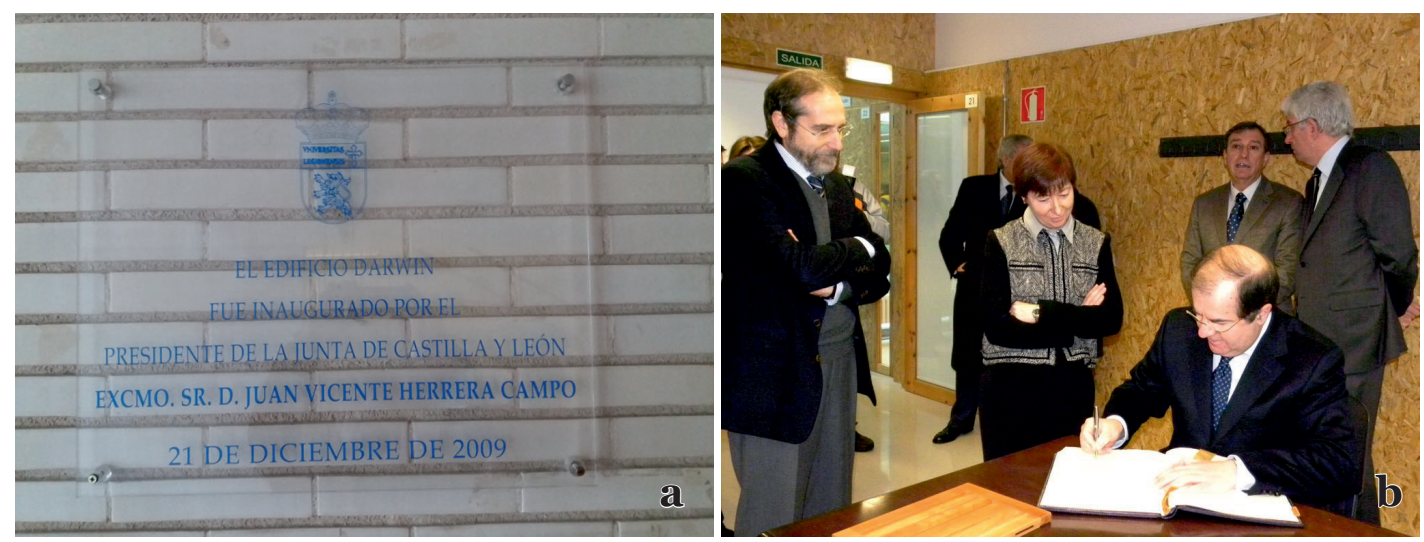

Figura 24. (a) Placa conmemorativa de la inauguración del edificio Darwin; (b) El Excmo. Sr. Presidente de la Junta D. Juan Vicente Herrera Campo firma en el libro de honor de la Facultad en el día de la inauguración del edificio Darwin, en presencia del Rector y de los decanos saliente (Dr. Pena Álvarez) y entrante (Dra. Razquín Peralta). Fotografía del archivo de la Universidad de León.

El nuevo edificio estaba ajustado a los requerimientos docentes que se habían impuesto en la universidad española a raíz de las disposiciones en desarrollo del Espacio Europeo de Educación Superior y que la Universidad de León y sobre todo la Facultad había acogido con calor y las correspondientes $M e$ morias de Verificación así lo recogieron. En él comenzaron a impartirse los estudios de los tres grados que ese mismo año se pusieron en marcha en sustitución de las tres licenciaturas que antes se impartían, en Biología, en Ciencias Ambientales y en Biotecnología.

El entorno de este edificio, y a propuesta de la Delegación de Sostenibilidad y Calidad Ambiental y la Oficina Verde de la Universidad, fue diseñado con microambientes de vegetación natural (Fig. 25), que es el único espacio ajardinado de esas características del campus.

50 Acta electrónica de la Junta de Facultad del día 22 de diciembre de 2009. 


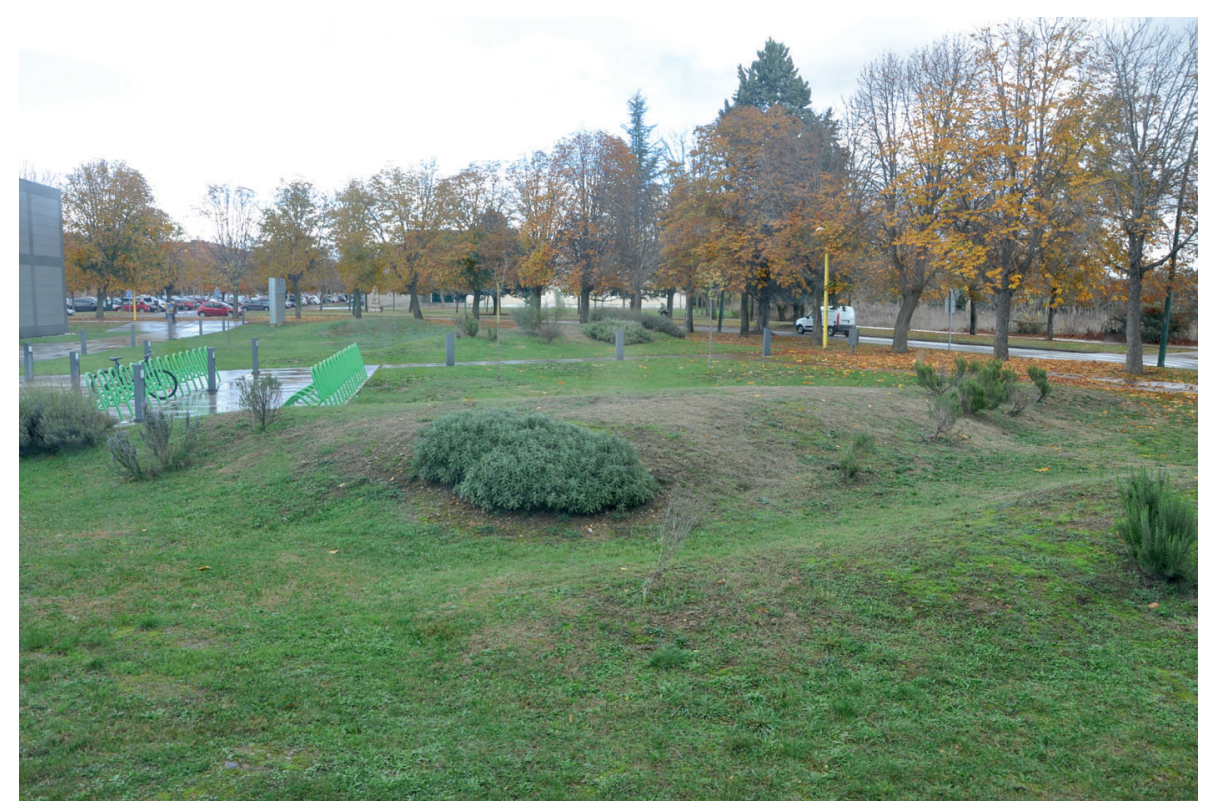

Figura 25. Ajardinamiento del entorno del edificio Darwin.

\section{Agradecimientos}

Los autores de este apunte histórico quieren agradecer la ayuda prestada en los diferentes apartados del recuerdo: a los que fueron Decanos de esta Facultad, y en especial a la Dra ${ }^{a}$. Rodríguez Otero y al Dr. Pena Álvarez, por sus puntualizaciones; a D. Luis Ameijide Montenegro, D. Luis Roy Ramos, Dña. Belén López Martínez, D. Enrique Ortega Lorenzo y D. Vicente Fernández Arias, por sus aportaciones técnicas sobre planos, proyectos y archivos; a D. Daniel de Luis de la Fuente por su colaboración en el capítulo fotográfico actual; y a todos los compañeros que contribuyeron con su opinión y arañaron en sus remembranzas. 